\title{
Article \\ MAP3Ke1/2 Interact with MOB1A/1B and Play Important Roles in Control of Pollen Germination through Crosstalk with JA Signaling in Arabidopsis
}

\author{
Juan Mei ${ }^{1}$, Pengmin Zhou ${ }^{1,2}$, Yuejuan Zeng ${ }^{1}$, Binyang Sun ${ }^{1}$, Liqun Chen ${ }^{1}$, De Ye ${ }^{1}$ and Xueqin Zhang ${ }^{1, *}$ \\ 1 State Key Laboratory of Plant Physiology and Biochemistry, College of Biological Sciences, China Agricultural \\ University, Beijing 100193, China; sz20173020125@cau.edu.cn (J.M.); zhoupengmin@genetics.ac.cn (P.Z.); \\ sz20163020123@cau.edu.cn (Y.Z.); s20203020244@cau.edu.cn (B.S.); chenliqun@cau.edu.cn (L.C.); \\ yede@cau.edu.cn (D.Y.) \\ 2 State Key Laboratory of Molecular Developmental Biology, Institute of Genetics and Developmental Biology, \\ Chinese Academy of Sciences, Beijing 100101, China \\ * Correspondence: kouyang@cau.edu.cn; Tel./Fax: +86-10-6273-4837
}

\section{check for}

updates

Citation: Mei, J.; Zhou, P.; Zeng, Y.; Sun, B.; Chen, L.; Ye, D.; Zhang, X. MAP3K $\varepsilon 1 / 2$ Interact with MOB1A/1B and Play Important Roles in Control of Pollen Germination through Crosstalk with JA Signaling in Arabidopsis. Int. J. Mol. Sci. 2022, 23, 2683. https:// doi.org/10.3390/ijms23052683

Academic Editors: Stefano Del Duca, Iris Aloisi and Giampiero Cai

Received: 29 January 2022

Accepted: 24 February 2022

Published: 28 February 2022

Publisher's Note: MDPI stays neutral with regard to jurisdictional claims in published maps and institutional affiliations.

Copyright: (C) 2022 by the authors. Licensee MDPI, Basel, Switzerland. This article is an open access article distributed under the terms and conditions of the Creative Commons Attribution (CC BY) license (https:// creativecommons.org/licenses/by/ $4.0 /)$.

\begin{abstract}
Restriction of pollen germination before the pollen grain is pollinated to stigma is essential for successful fertilization in angiosperms. However, the mechanisms underlying the process remain poorly understood. Here, we report functional characterization of the MAPKKK kinases, MAP3K $\varepsilon 1$ and MAP3K 2 2, involve in control of pollen germination in Arabidopsis. The two genes were expressed in different tissues with higher expression levels in the tricellular pollen grains. The

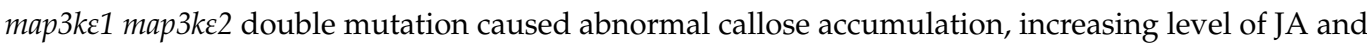
precocious pollen germination, resulting in significantly reduced seed set. Furthermore, the map3ke1 map3k\&2 double mutations obviously upregulated the expression levels of genes in JA biosynthesis and signaling. The MAP3K $\varepsilon 1 / 2$ interacted with MOB1A/1B which shared homology with the core components of Hippo singling pathway in yeast. The Arabidopsis mob1a mob1b mutant also exhibited a similar phenotype of precocious pollen germination to that in map3ke1 map $3 k \varepsilon 2$ mutants. Taken together, these results suggested that the MAP3K $\varepsilon$ s interacted with MOB1s and played important role in restriction of the precocious pollen germination, possibly through crosstalk with JA signaling and influencing callose accumulation in Arabidopsis.
\end{abstract}

Keywords: MAP3Kes; MOB proteins; JA; precocious germination; Arabidopsis

\section{Introduction}

During anthesis of flowering plants, the mature pollen grains are released from the dehiscent anther and delivered to the stigma of the pistil. After its recognition with the stigmatic cells, the pollen grain hydrates and germinates, generating a pollen tube, which further carries the two sperm cells into the embryo sac for double fertilization [1,2]. Therefore, pollen germination and pollen tube growth are essential for successful sexual reproduction in angiosperm plants. Defects in pollen grain germination or pollen tube growth will cause male sterility. Many factors have been identified as the positive regulators of pollen germination and pollen tube growth, such as calmodulin, $\mathrm{Ca}^{2+}$, phosphatidylinositol, $\mathrm{H}^{+}, \mathrm{NO}$, protein kinase, $\mathrm{ROS}, \mathrm{pH}$, etc. [3-7]. Studies also show that restriction of pollen germination before the pollen grain is pollinated onto the stigma, is also significant for successful fertilization. Loss of the germination-restrictive functions will cause precocious germination of the pollen grains in the anthers before they are pollinated to the stigma, leading to failure of fertilization. For example, the raring-to-go ( $r t g)$ mutant pollen grains exhibit precocious germination in the anthers at the bicellular pollen stage due to aberrant callose deposition in the pollen grains [8]. Furthermore, Arabidopsis plantacyanin overexpressionresults in abnormal callose deposition in pollen walls and leads to a few of the transgenic 
pollen grains precociously germinating in the indehiscent anther [9]. These results and more and more newly identified evidence show that the abnormal callose deposition is related to precocious germination of pollen grains. The direct evidence is achieved from the characterization of callose synthases. Both mutations in Glucan Synthase-Like 10/Callose Synthase 9 (GSL10/Cals9) and overexpression of Glucan Synthase-Like 2/Callose Synthase 5 (GSL2/Cals5) could cause aberrant callose deposition in bicellular pollen grains which precociously germinate inside the anthers [10]. In addition, several genes, which are involved in synthesis of the important substances and hormones are also important for controlling the precocious pollen germination. The Arabinogalactan Proteins (AGPs) are important components of the pollen walls. Loss of AGP6, AGP11, and fasciclin-like AGPS (FLAs) cause defects in pollen development and germination [11,12]. The nicotinate/nicotinamide mononucleotide adenyltransferase (NMNAT) is a key enzyme for NAD biosynthesis. Mutation in NMNAT leads to precocious pollen germination in anthers [13]. Moreover, the GTP-Binding Protein Related1 (GPR1) is also involved in the restriction of pollen precocious germination, and a loss of its function causes precocious pollen germination at the triple cellular stage in the anthers [14].

JA is an important hormone for plant growth, which also regulates anther development and pollen maturation [15,16]. Mutations of the genes involved in the JA biosynthesis and signaling pathway can affect both vegetative and reproductive organ development in plants. For example, the fatty acid desaturation (fad) [17], coronatine insensitive protein 1 (coi1) [18], 2-oxophytodienoic acid reductase (opr3) [19], delayed-dehiscence1 (dde1) and dde2 [20,21], defective in anther dehiscence 1 (dad1) [22], and allene oxide synthase (aos) [23] are all defective in reproductive organ development. Methyl jasmonate (MeJA) influences pollen germination and pollen tube elongation of Pinus nigra in vitro [24]. Arabidopsis $D A Y U(D A U)$ encodes the peroxisome membrane protein ABERRANT PEROXISOME MORPHOLOGY 9 (APEM9), which regulates pollen germination by participating in JA biosynthesis [25]. JINGUBANG (JGB) containing the WD40 domain regulates JA biosynthesis via interaction with TEOSINTE BRANCHED1/CYCLOIDEA/PROLIFERATING CELL NUCLEAR ANTIGEN FACTOR 4 (TCP4)transcription factor, affecting pollen germination, indicating that high-level JA could promote pollen germination [26]. Taken together, restriction of precocious pollen germination before the pollen grains are pollinated on the stigma is controlled by a complex mechanism, which remains largely unknown.

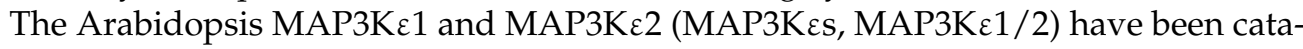
logued to the MAPK protein kinase family [27]. The phylogenetic analysis shows that the Arabidopsis MAP3K $\varepsilon$ s share the closest similarity to the Cdc7 from Schizosaccharomyces pombe and Cdc15 from Saccharomyces cerevisiae [28]. Cdc7 is a component of the septation initiation network (SIN) which regulates septum formation after chromosome segregation in cell division [29]. The protein kinase Cdc15 phosphorylates and activates the downstream Dbf2/20-Mob1 complex to participate in mitotic exit network (MEN) [30]. The core components of the Hippo pathway and MEN/SIN pathway are strongly conserved from yeast to humans, including the upstream factor Germinal Center Kinases (GCK/Ste20) protein kinase, the downstream NDR protein kinase, and the NDR co-activator MOB protein [31,32]. There are few reports on the Hippo signaling pathway in plants. For example, SIK1, a Hippo/STE20 homolog can interact with MOB1A and MOB1B, and regulates cell proliferation and expansion in Arabidopsis [33]. MOB1A is required for sporophyte and gametophyte development and plays a critical role in auxin-mediated plant development [34-36]. MOB1A and $M O B 1 B$ also regulate JA accumulation and root development [37]. Recently, three NDR kinases, NDR2/4/5, and MOB1A/1B, which function redundantly, are identified as being required for preventing precocious pollen germination [38]. This result indicates that the core components of Hippo pathway and MEN/SIN pathway in plants are also likely to be involved in the control of pollen precocious germination. However, their signaling mechanisms underlying the restriction of pollen germination remain unclear. 
In this study, we performed functional characterization of the Arabidopsis proteins

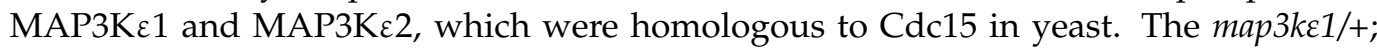

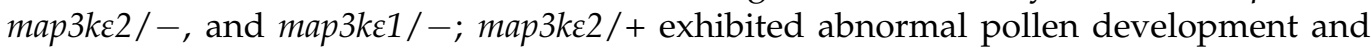
precocious pollen germination in the dehiscent anthers. Part of the mature mutant pollen grains had abnormal callose deposition. Furthermore, the expression levels of many JA-

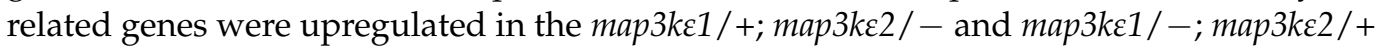
mutants, consistent with the increase of the JA content in the mutants. The proteinprotein interaction assays, including yeast two-hybrid ( $\mathrm{Y} 2 \mathrm{H})$, Co-Immunoprecipitation (Co-IP), and luciferase complementation image (LCI) assays, showed that MAP3K $\varepsilon 1 / 2$ could interact with MOB1A/1B, respectively. Moreover, genetic analysis indicated that the

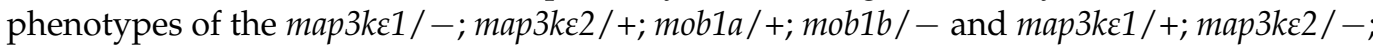
mob1a/+; mob1b/ - were similar to that of the mob1a/+;mob1b/ - mutant. Together, our study suggested that the MAP3Kes may interact with the MOB1s and regulated pollen germination through influencing JA homeostasis in Arabidopsis pollen.

\section{Results}

\subsection{MAP3Ke1/2 Were Expressed Ubiquitously in Different Tissues}

Phylogenetic analysis showed that the MAP3Kes existed widely in both monocotyledons and dicotyledons, such as Zea mays, Oryza sativa, and Glycine max, and had characteristics similar to those of $\mathrm{Cdc} 15$ and $\mathrm{Cdc} 7$ in yeast. Further structural analysis indicated that MAP3KE1/2 had conserved N-terminal kinase domain that shared high homology with the domain in STKc_Cdc7_like protein kinase (Figure S1). Quantitative real-time PCR (qRT-PCR) and promoter activity assays were further performed to investigate their expression. The results of qRT-PCR showed that $M A P 3 K \varepsilon 1 / 2$ were expressed widely in different Arabidopsis tissues, especially higher in mature pollen grains and siliques (Figure S2A). For promoter::GUS activity assays, the two promoter fragments of $M A P 3 K \varepsilon 1 / 2$ were fused with the GUS reporter gene in Ti-derived vector pCAMBIA1300 and introduced into wildtype plants, respectively. Consistent with qRT-PCR results, GUS activity was detected

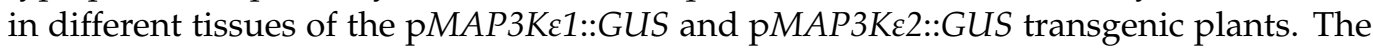
higher GUS activities also were detected in mature pollen grains (Figure S2B-Q). These results suggested that $M A P 3 K \varepsilon 1$ and $M A P 3 K \varepsilon 2$ may play wide spectrum of roles in different Arabidopsis tissues, including pollen development and pollen tube growth.

\subsection{The map3ke1 map3ke2 Double Mutant Enhanced Pollen Germination}

Previous study showed that the single mutants generated by T-DNA insertion in either $M A P 3 K \varepsilon 1$ or $M A P 3 K \varepsilon 2$ displayed normal development, while the double mutant combination showed abnormal pollen development [39], indicating that MAP3KE1 and $M A P 3 K \varepsilon 2$ functioned redundantly and played important roles in pollen development. To further investigate the functions of $M A P 3 K \varepsilon 1 / 2$ in plant reproductive development, we obtained the mutants from the Arabidopsis Biological Resource Center (ARBC). In the SALK_133360C, T-DNA was inserted in the 17th exon of MAP3Ke1, 4534 bp downstream of ATG. In the SALK_084747C, T-DNA was inserted in the 6th intron of MAP3Ke2, $969 \mathrm{bp}$ downstream of ATG (Figure S3A). The sites of T-DNA insertion were further confirmed by PCR using gene-specific and T-DNA border primers. The RT-PCR results indicated that the T-DNA-insertion mutants were homozygous (Figure S3B-E). Neither MAP3KE1

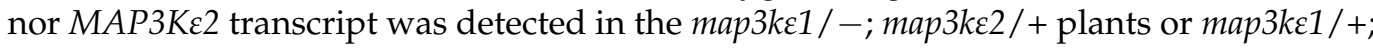

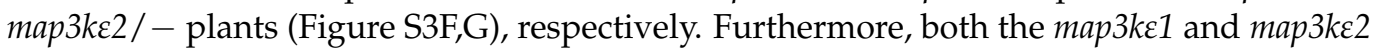
plants showed the same growth patterns as normal as that of wild-type plants. Then, the double mutants were generated by crosses of the single mutants. No double homozygous mutant plant was obtained. Therefore, two types of heterozygous mutants, namely

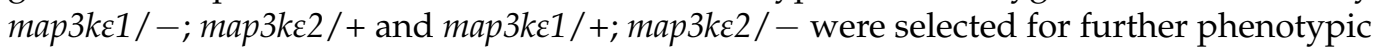
analyses. Their vegetative growth showed no significant difference, compared to that of

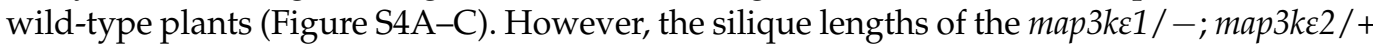

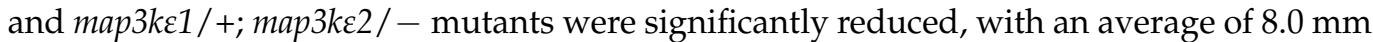


$(n=107)$ and $9.6 \mathrm{~mm}(n=162)$, respectively, much shorter than $12.00 \mathrm{~mm}(n=100)$ in wild-type plants (Figure S4D-G). The mutants produced an average of 34.0 and 37.6 seeds per silique, respectively, in contrast to an average of 48.2 seeds per silique in the wild-type plants. (Figure $\mathrm{S} 4 \mathrm{H}-\mathrm{N}$ ). To investigate the causes for the reduced seed set, the mature pollen grains at the late tricellular stage were examined by scanning electronic microscope (SEM). The results showed that $50.1 \%(n=2226)$ of the map $3 k \varepsilon 1 /-;$ map $3 k \varepsilon 2 /+$ and $51.2 \%$ ( $n=2497)$ of map3ks1/+; map $3 k \varepsilon 2 /$ - mutant pollen grains exhibited an abnormal morphology (Figure 1A-F, V). Alexander's staining assays showed that many pollen grains from the two heterozygous mutants had an abnormal staining pattern, compared to those in red from wild-type plants (Figure 1G-I). DAPI staining showed that many mature pollen grains from the two heterozygous mutants were dead, as demonstrated by their loss of DAPI staining (Figure 1J-O). The aniline blue staining showed that $26.8 \%(n=2940)$ of the map $3 k \varepsilon 1 /-$; map $3 k \varepsilon 2 /+$ and $23.5 \%(n=3029)$ of the map3k $\varepsilon 1 /+$; map $3 k \varepsilon 2 /$ - mutant pollen grains at the tricellular stage exhibited abnormal callose accumulation, compared to those in wild-type plants (Figure 1P-U,W,X).

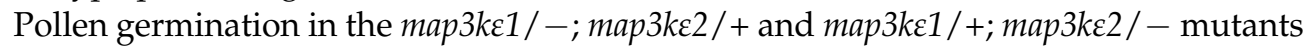
were examined, respectively. The mature pollen grains were collected from the two heterozygous mutants and wild-type plants and cultured on the pollen germination medium, respectively. The time-course of germination rate in vitro was made by statistic method. At $1 \mathrm{~h}$ after being cultured (HAC), $6 \%(n=2620)$ of wild-type pollen grains germinated. In contrast, $17 \%(n=1111)$ of the pollen grains from map3ke1/-; map $3 k \varepsilon 2 /+$ and $16 \%$ $(n=1098)$ of the pollen grains from the map $3 k \varepsilon 1 /+;$ map $3 k \varepsilon 2 /-$ germinated in vitro. At two HAC, $21 \%(n=667)$ of wild-type pollen grains germinated, whereas germination rate of the pollen grains from map $3 k \varepsilon 1 /-;$ map $3 k \varepsilon 2 /+$ and map $3 k \varepsilon 1 /+;$ map $3 k \varepsilon 2 /$ - mutants increased by $53 \%(n=1209)$ and $44 \%(n=1187)$, respectively. At six HAC, the germination rates of the pollen grains from the two double mutants were close to $70 \%$, with no significant difference between wild-type plants and the two double mutants (Figure S5A-L,R). These results indicated that the MAP3KEs negatively regulated pollen germination.

\subsection{The map3ke1 map3ke2 Double Mutant Pollen Grains Precociously Germinated in the Dehiscent Anthers}

The microscope observation showed that the pollen grains on the stigma in the map $3 k \varepsilon 1 /-;$ map $3 k \varepsilon 2 /+$ and map $3 k \varepsilon 1 /+;$ map $3 k \varepsilon 2 /-$ plants were less than those on the

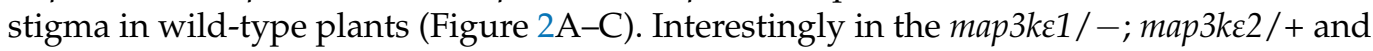
map $3 k \varepsilon 1 /+;$ map3ke2/ - mutants, the mature pollen grains at the late tricellular stage germinated precociously and produced pollen tube in the dehiscent anthers. In particular, $37.2 \%$

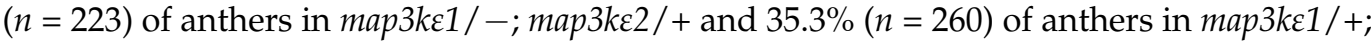
map $3 k \varepsilon 2 /$ - exhibited precocious pollen germination, respectively, contrast to that no or rare precocious pollen germination was observed in the wild-type plants (Figure 2D-N). These results further indicated that the MAP3Kes were negative regulator of pollen germination before the pollen grains were pollinated on the stigma. 

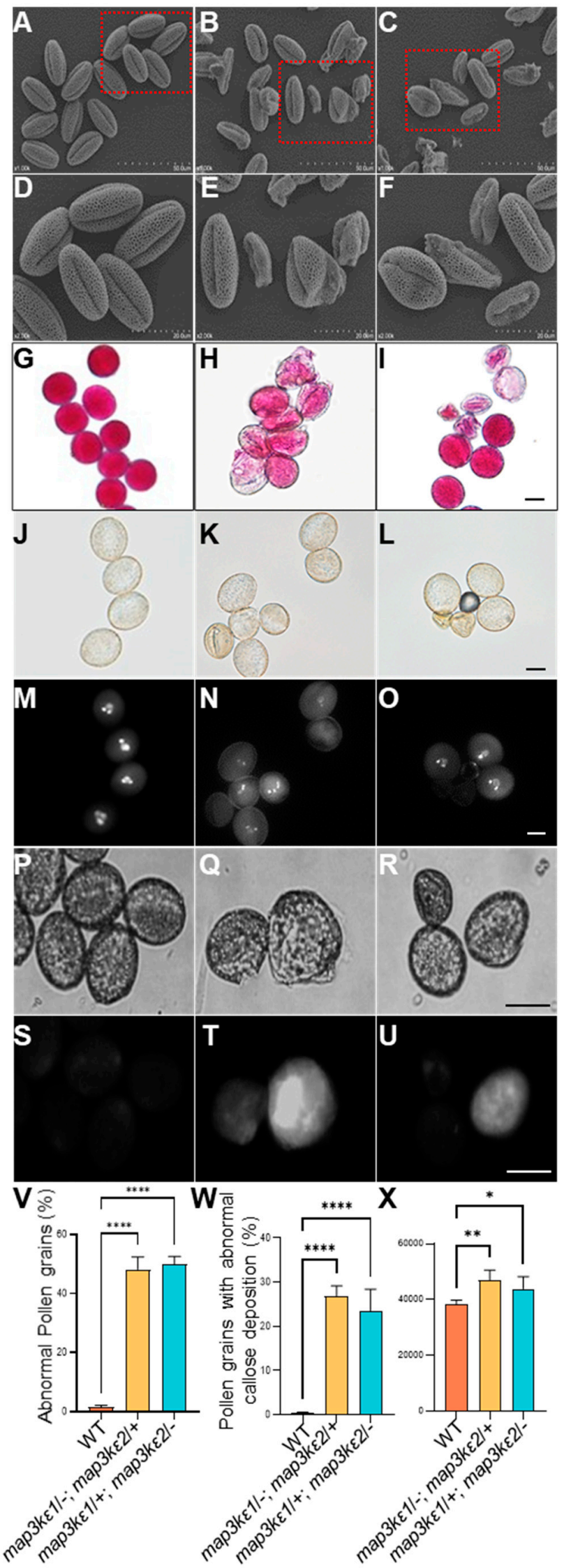

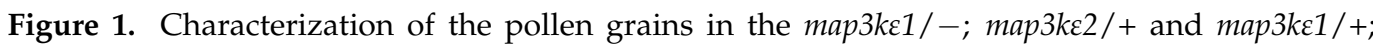
map3ke2/- mutants. (A-C): SEM images of mature pollen grains from the dehiscent anthers of 


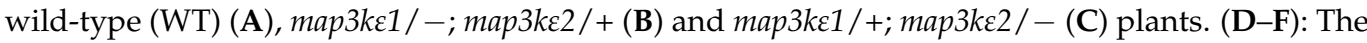
magnified images of the red-boxed areas in $(\mathbf{A}-\mathbf{C})$, respectively. $(\mathbf{G}-\mathbf{I})$ : The Alexander-stained pollen grains from wild-type (WT) plants $(\mathbf{G})$, map $3 k \varepsilon 1 /-;$ map3k $2 /+(\mathbf{H})$, and map $3 k \varepsilon 1 /+;$ map $3 k \varepsilon 2 /-(\mathbf{I})$

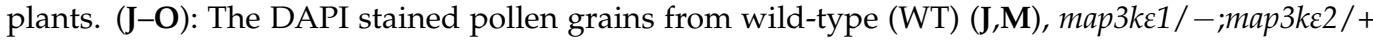

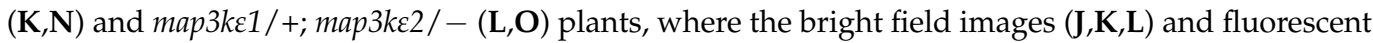
images (M-O) were shown, respectively. (P-U): Aniline blue-stained mature pollen grains from wild-

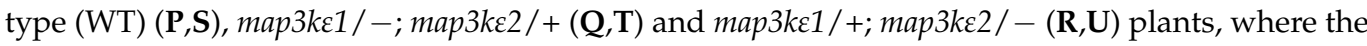
bright field images $(\mathbf{P}-\mathbf{R})$ and fluorescent images $(\mathbf{S}-\mathbf{U})$ were shown, respectively. $(\mathbf{V})$ : Comparison of

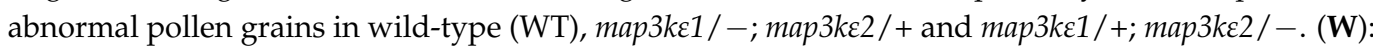

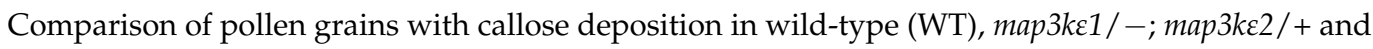

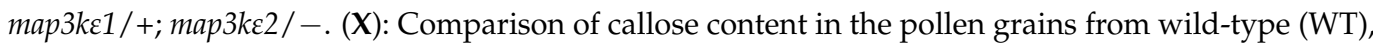

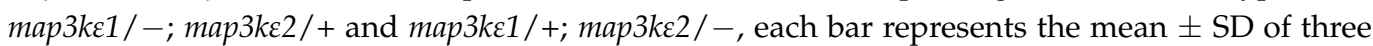
independent experiments. Different letters represent significant difference at $p<0.05,{ }^{* *} p<0.01$, **** $p<0.0001$ (one-way ANOVA, Tukey post-test). Bars $=10 \mu \mathrm{m}$ in $(\mathbf{G}-\mathbf{U})$.

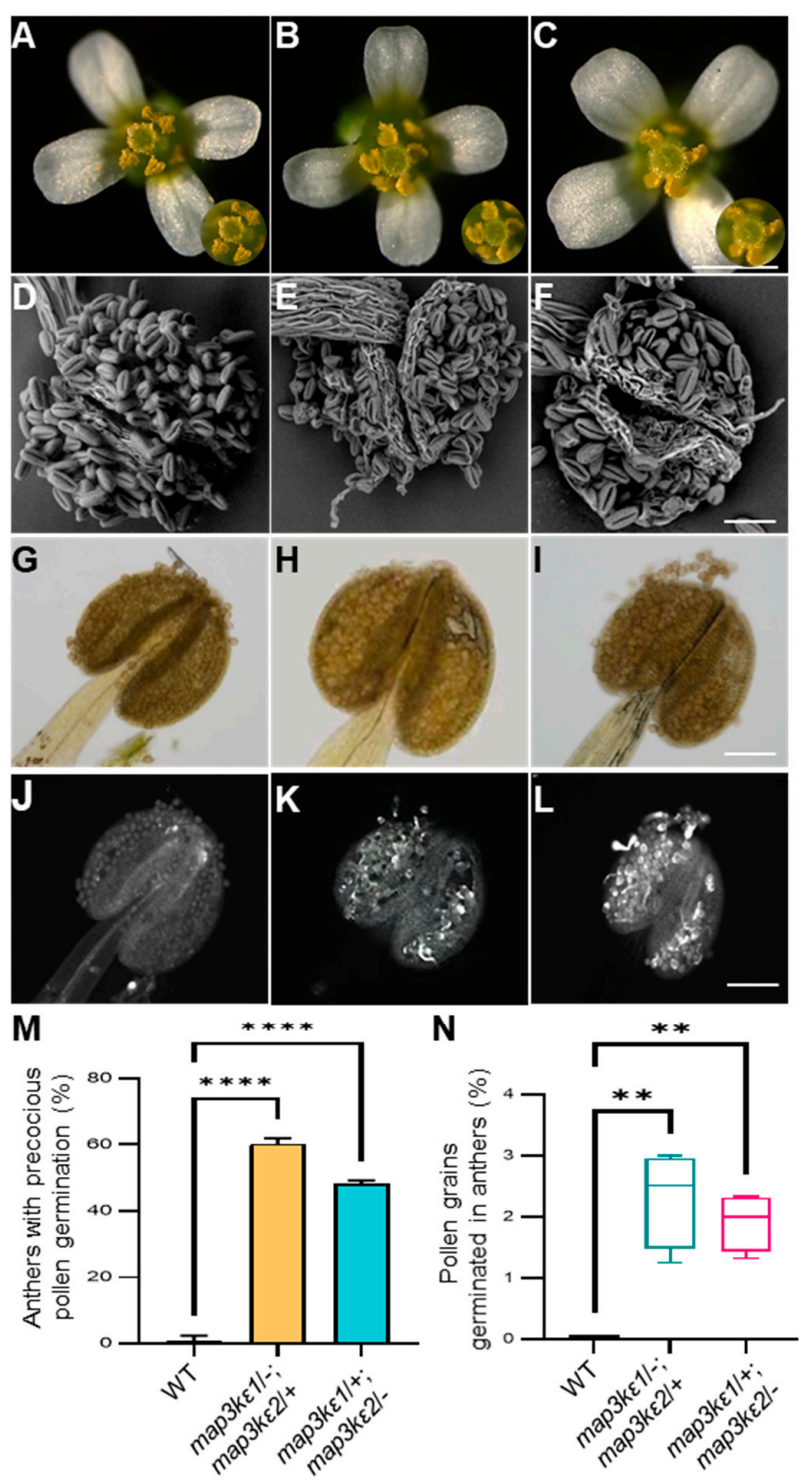

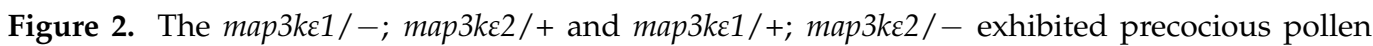
germination in the dehiscent anthers. (A-C): The flowers at the floral stage 13 of wild-type (WT) 


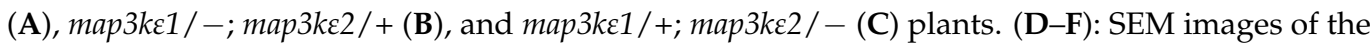

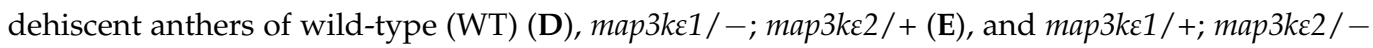
(F) plants. (G-L): The aniline blue-stained dehiscent anthers of wild-type (WT) $(\mathbf{G}, \mathbf{J})$, map3ke1/-;

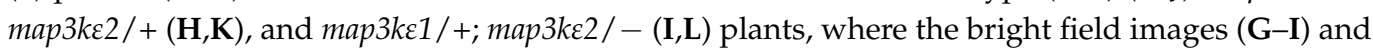
fluorescent images (J-L) were shown, respectively. (M): A comparison of the dehiscent anthers

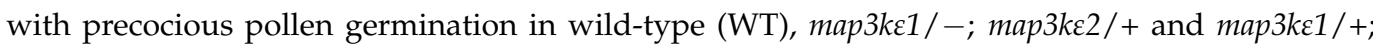
map3ke2/-. (N): A comparison of precociously germinating pollen grains in the dehiscent anthers

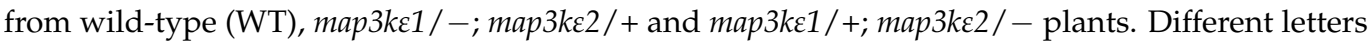
represent significant difference at ${ }^{* *} p<0.01,{ }^{* * * *} p<0.0001$ (one-way ANOVA, Tukey post-test). Bars $=1 \mathrm{~mm}$ in $(\mathbf{A}-\mathbf{C}), 100 \mu \mathrm{m}$ in $(\mathbf{D}-\mathbf{L})$.

\subsection{MAP3KE1/2 Interacted with $M O B 1 A / 1 B$}

Our previous study found that $n d r 2 / 4 / 5$ and mob1a/+; mob1b/- mutants also had precocious pollen germination in dehiscent anthers [38]. To investigate the function of MAP3K $\varepsilon 1 / 2$ proteins, according to the components in the Hippo pathway that existed in yeast and the phylogenetic analysis, MAP3K $\varepsilon 1 / 2$ may be analogies of GCK/Ste20 in yeast and interacted with the conserved NDR proteins. To confirm this interaction, both yeast two-hybrid $(\mathrm{Y} 2 \mathrm{H})$ and luciferase complementation image (LCI)assays were performed, respectively. In the $\mathrm{Y} 2 \mathrm{H}$ experiment, NDR2/4/5 could not interact with MAP3K $\varepsilon 1 / 2$, respectively. LCI assays showed that NDR2 and NDR4 could interact with MAP3K $1 / 2$, respectively, whereas NDR5 could not interact with MAP3K $1 / 2$ (Figure S6). These results implied that MAP3K $1 / 2$ maybe not interoperate with NDR2/4/5.

Previous studies showed that CGK/Ste20 protein can interact with the MOB-NDR complex [31,32], we investigated whether MAP3K $\varepsilon 1 / 2$ could interact with MOB1A/1B. Three methods for protein interaction assays, namely $\mathrm{Y} 2 \mathrm{H}$, co-immunoprecipitation (CoIP), and LCI assays, were applied. The $\mathrm{Y} 2 \mathrm{H}$ results showed that MAP3K $\varepsilon 1 / 2$ proteins could interact with MOB1A and MOB1B proteins in yeast cells, respectively (Figure 3A). Co-IP results showed that MOB1A-mcherry and MOB1B-mcherry could be pulled down by GFP-MAP3K $\varepsilon 1$ and GFP-MAP3K $\varepsilon 2$, respectively, indicating that MAP3K $\varepsilon 1 / 2$ proteins could interact with MOB1A/1B proteins in vivo (Figure 3B). Finally, LCI analysis also showed that MAP3K $1 / 2$ could interact with MOB1A and MOB1B in $N$. benthamiana leaves, respectively (Figure $3 \mathrm{C}-\mathrm{J}$ ). The results demonstrated that MAP3K $\varepsilon 1 / 2$ could interact with MOB1A and MOB1B.

\subsection{MAP3Ke1/2 Were Co-Localized with MOB1A/1B in the Cytoplasm and Plasma Membrane}

To investigate whether the MAP3Kes proteins could be co-localized with the MOB1s

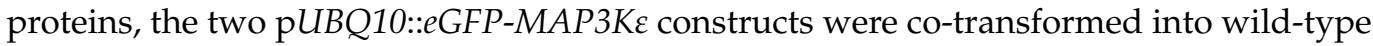
plants with $\mathrm{pUBQ10::MOB1A-mcherry}$ or pUBQ10::MOB1B-mcherry, respectively. The results showed that eGFP-MAP3K $\varepsilon 1$ signals were co-localized in the cytoplasm, and plasma membrane with the signals of MOB1A-mcherry and MOB1B-mcherry, respectively. Similar results were also achieved from the assays for MAP3K 2 2, showing that MAP3K $\varepsilon 2$ was co-localized with MOB1A/1B in the cytoplasm, and plasma membrane (Figure 4A-H). These results also suggested that MAP3K $\varepsilon 1 / 2$ interacted with MOB1A/1B and probably function in the cytoplasm and plasma membrane. 

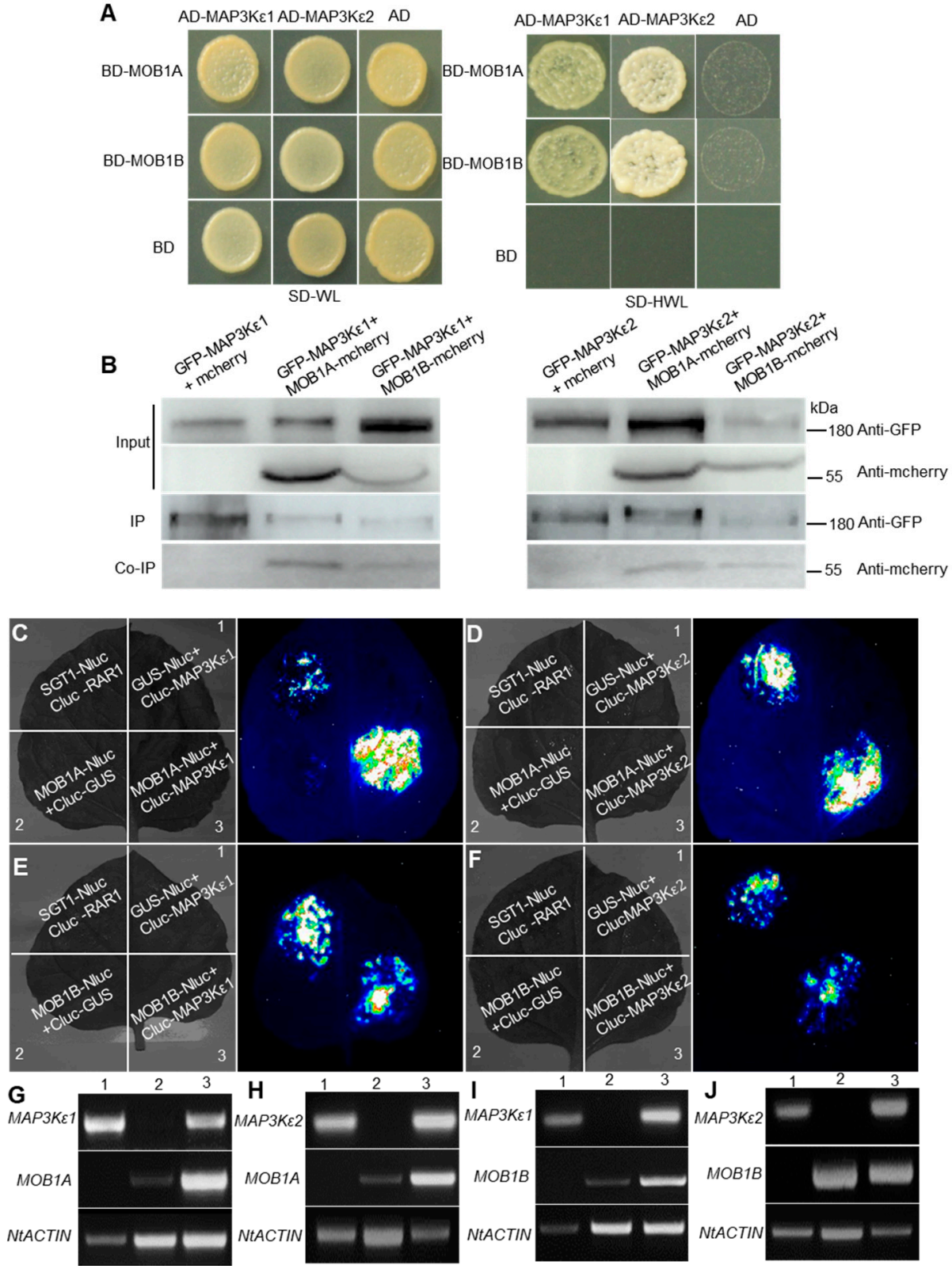

Figure 3. MAP3Kes proteins interacted with the MOB1s proteins. (A): The MAP3Kes proteins interacted with MOB1s proteins in the yeast two-hybrid assay. The interaction was determined by yeast growth on the medium lacking His $(\mathrm{H}), \operatorname{Trp}(\mathrm{W})$, and Leu $(\mathrm{L})$. (B): Co-IP of MAP3Kes proteins and MOB1s proteins in vivo. The $N$. benthamiana leaves were transfected with pUBQ10::GFP-MAP3KE1/2 and $\mathrm{pUBQ10::mcherry}$ or $\mathrm{p} U B Q 10:: G F P-M A P 3 K \varepsilon 1 / 2$ and $\mathrm{p} U B Q 10:: M O B$ 1A/1B-mcherry. The total protein extracts were immunoprecipitated with GFP Sepharose beads. Input and immunoprecipitated proteins were detected with anti-GFP and anti-mcherry antibodies. (C-F): MAP3Kes proteins interacted with MOB1s proteins in the luciferase complementation image (LCI) assays. (G): RT-PCR analysis for gene expression in the LCI assay of (C). The numbers represent different experimental combinations marked in (C). (H): RT-PCR analysis for gene expression in the LCI assay of (D). The numbers represent different experimental combinations marked in (D). (I): RT-PCR analysis for gene expression in the LCI assay of (E). The numbers represent different experimental combinations marked in (E). (J): RT-PCR analysis for gene expression in the LCI assay of (F). The numbers represent different experimental combinations marked in (F). The expression of $N$. benthamiana gene ACTIN as control for the internal standard. 

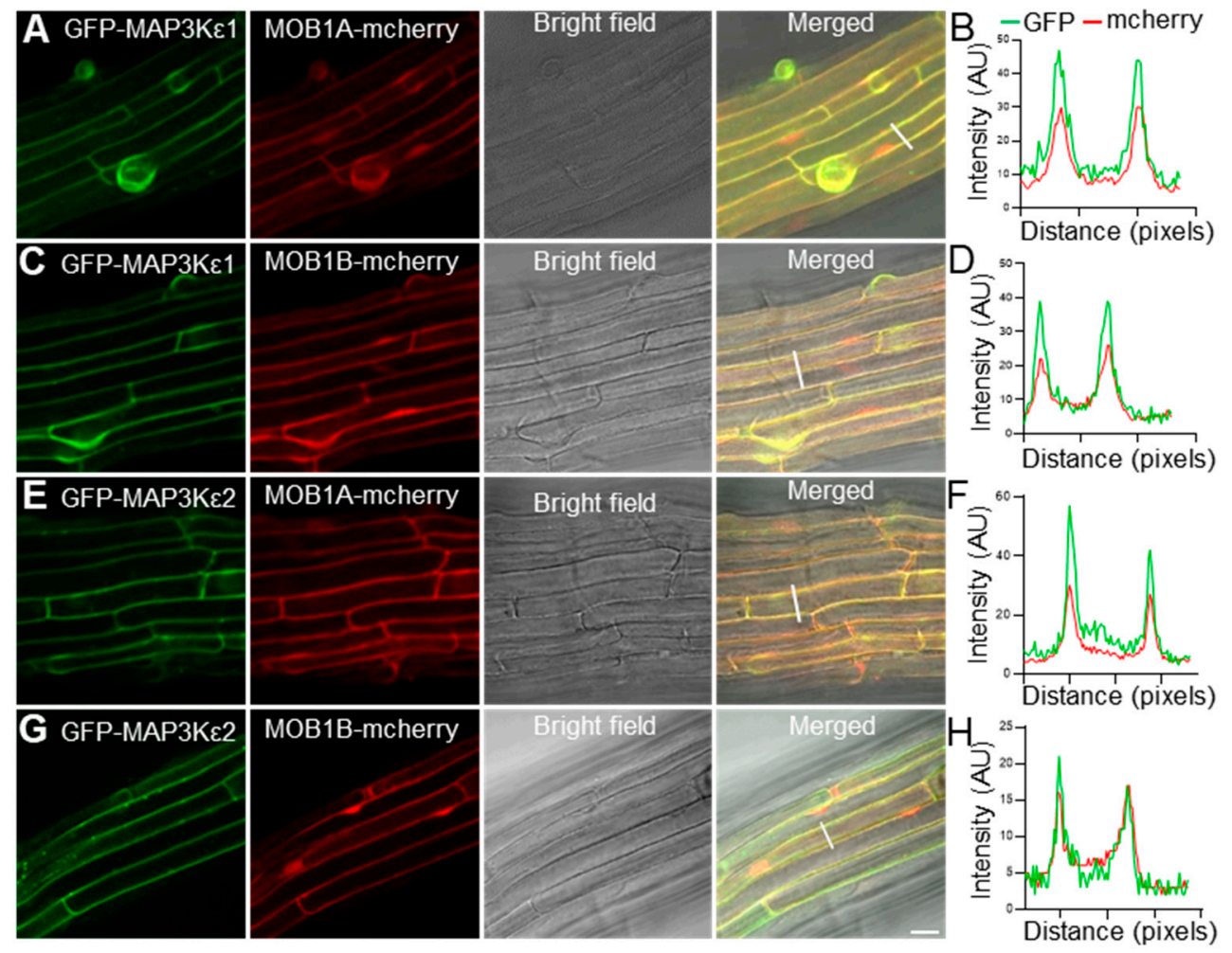

Figure 4. Subcellular localization patterns of MAP3KEs and MOB1s proteins. (A): The fluorescent images of a root from the pUBQ10::eGFP-MAP3Kع1 and pUBQ10::MOB1A-mcherry co-transgenic plant. (B): The fluorescence intensity distribution in the crossed regions (white lines) of (A). (C): The


transgenic plant. (D): The fluorescence intensity distribution in the crossed regions (white lines) of (B). (E): The fluorescent images of a root from the pUBQ10::eGFP-MAP3KE2 and pUBQ10::MOB1A-mcherry co-transgenic plant. (F): The fluorescence intensity distribution in the crossed regions (white lines) of (E). (G): The fluorescent images of a root from the pUBQ10::eGFP-MAP3KE2 and pUBQ10::MOB1Bmcherry co-transgenic plant. $(\mathbf{H})$ : The fluorescence intensity distribution in the crossed regions (white lines) of (G). Bars $=20 \mu \mathrm{m}$ in $(\mathbf{A}, \mathbf{C}, \mathbf{E}, \mathbf{G})$.

\subsection{JA Enhanced Pollen Germination}

A recent study revealed that $A t M O B 1$ s regulated JA accumulation subject to the MYC2-mediated JA signaling [37]. Therefore, we further investigated the expression levels of the genes in JA synthesis or signal pathway in the map3ke1/-; map3ke2/+ and

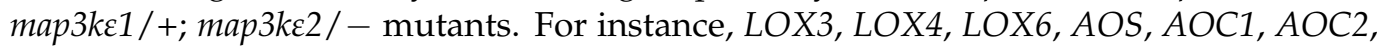
OPR3, CYP94B3, JOX3, and JAR1 which are involved in JA biosynthesis and metabolism,

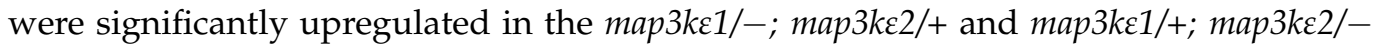
mutants (Figure 5A). JAZ1, JAZ2, JAZ5, JAZ9, JAZ10, and MYC2 in the JA signal pathway

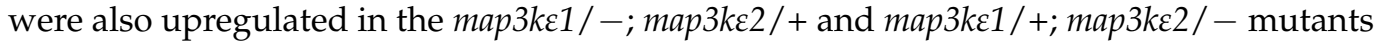
(Figure 5B). Then, endogenous JA contents were measured in the mutant plants using the ultra-performance liquid chromatography (UPLC) combined with mass spectrometry.

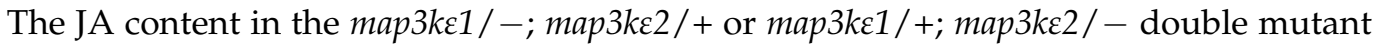
was increased compared with that in wild-type plants (Figure 5C). These results indicated that MAP3K $\varepsilon 1$ and MAP3K 2 maybe negatively regulate JA accumulation to maintain the homeostasis of JA level for restriction precocious pollen germination. 

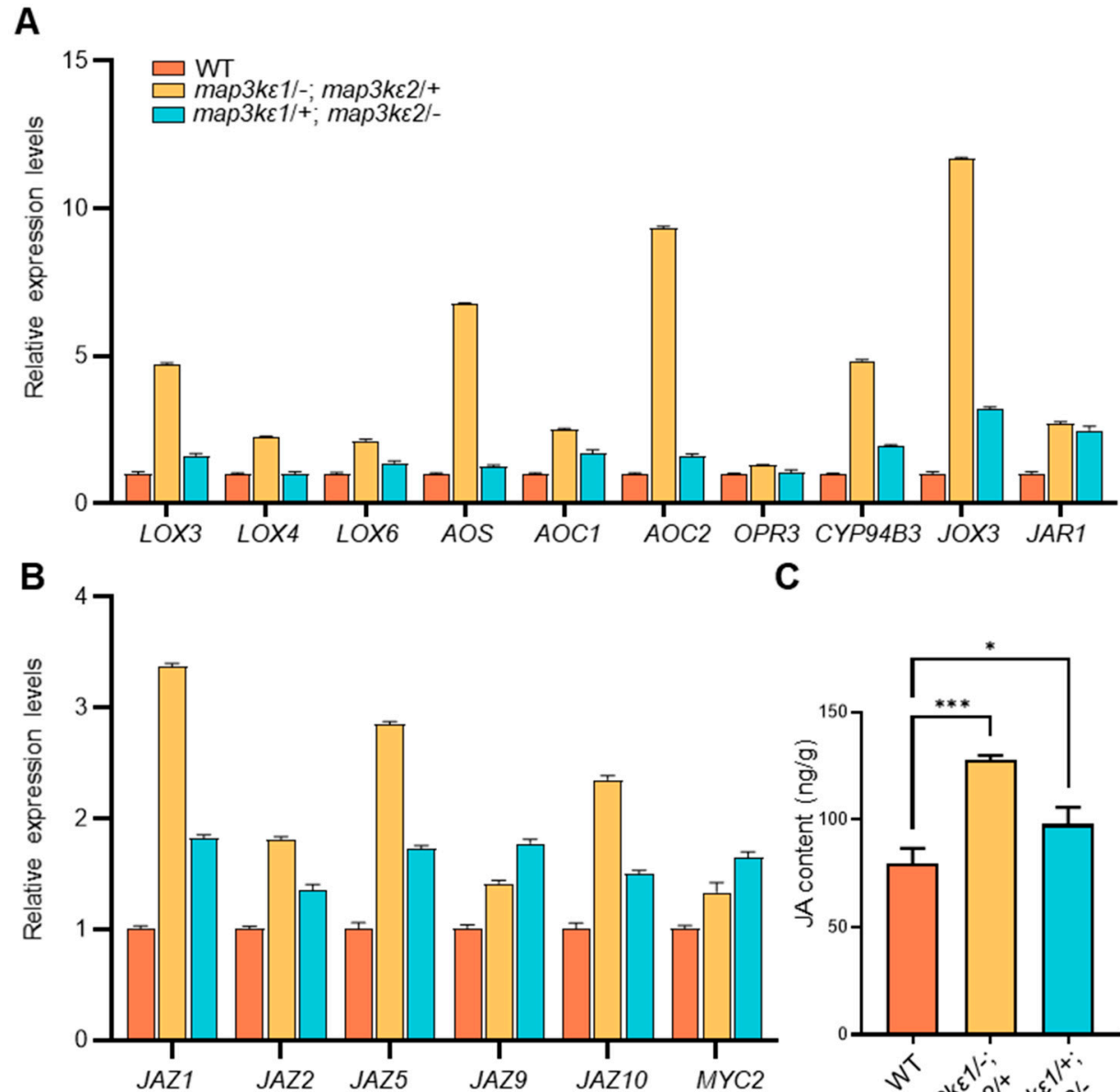

C

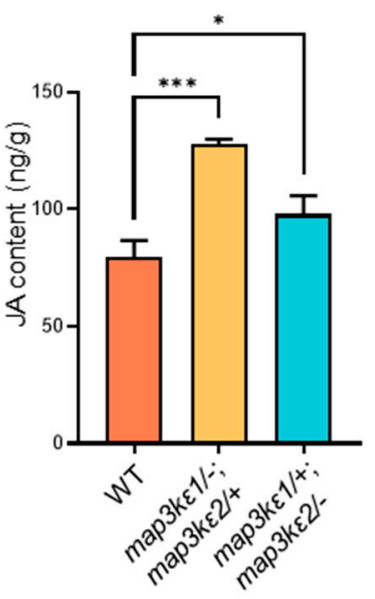

Figure 5. Expression of the genes in JA biosynthesis, metabolism, signaling, and JA contents were

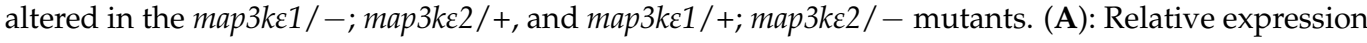
of JA biosynthesis, metabolism-related genes in mature pollen of wild-type (WT) and the map3ks1/-;

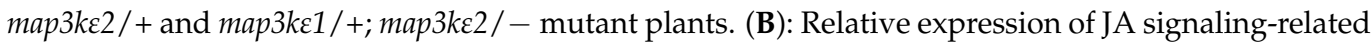

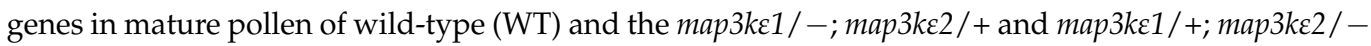
mutant plants. ACTIN2 was used as the internal control. (C): Measurement of the JA contents in the

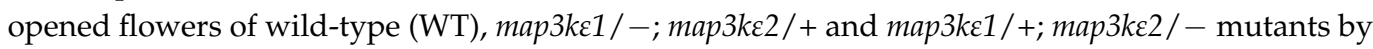
using UPLC-MS. Each bar represents the mean \pm SD of three independent experiments. Different letters represent significant difference at ${ }^{*} p<0.05,{ }^{* * *} p<0.001$ (one-way ANOVA, Tukey post-test).

\subsection{Genetic Interaction between $M A P 3 K \varepsilon 1 / 2$ and $M O B 1 A / 1 B$}

To explore the genetic interaction of $M A P 3 K \varepsilon 1 / 2$ and $M O B 1 A / 1 B$, we generated two

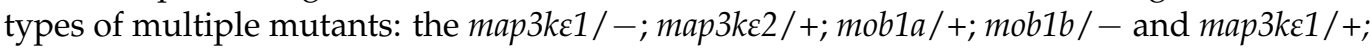

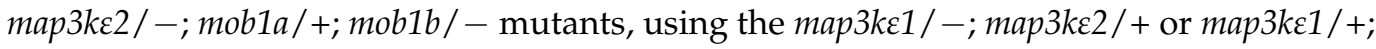
map3ke2/ - mutant plants as female to cross with mob1a/+; mob1b/- plant, respectively. The phenotypic analysis showed that these mutants also exhibited precocious pollen germination in dehiscent anthers. In particular, $80 \%(n=157)$ dehiscent anthers of the

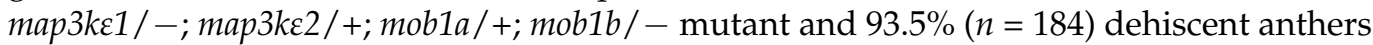
of the map $3 k \varepsilon 1 /+;$ map $3 k \varepsilon 2 /-;$ mob1a/+; mob1b/ - mutant showed precocious pollen germination, similar to $87 \%(n=216)$ anthers with precocious pollen germination in the mob1a/+; mob1b / - plant (Figure 6A-M). Meanwhile, we also measured JA contents in the map3ke1 / - ;

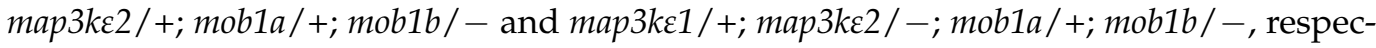
tively. JA contents were significantly higher than those in the map3k $\varepsilon 1 /-;$ map $3 k \varepsilon 2 /+$ and

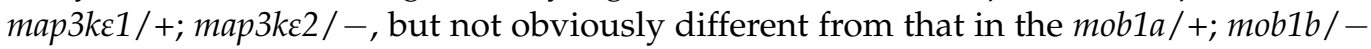


(Figure $6 \mathrm{~N}$ ). These results indicated that $M A P 3 K \varepsilon 1 / 2$ work as the upstream factors to interact with $M O B 1 A / 1 B$ in regulation of pollen germination.
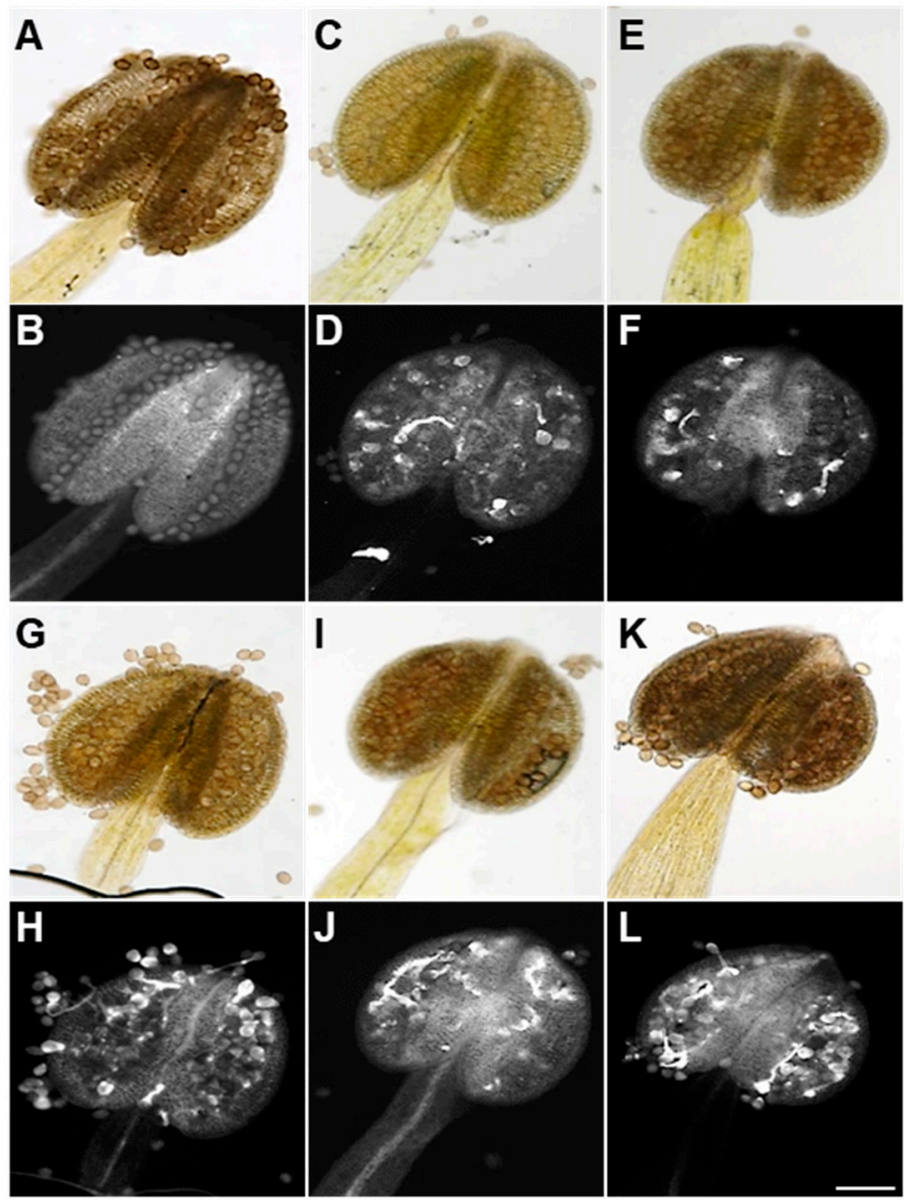

M

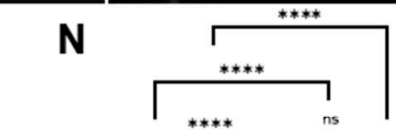

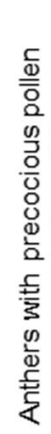
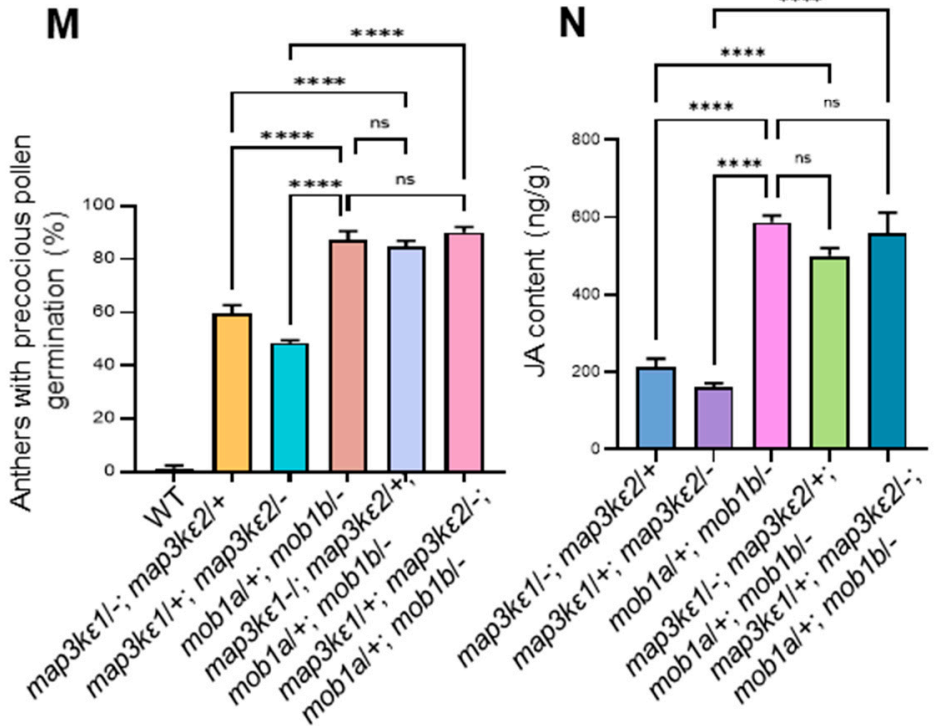

Figure 6. Genetic interaction of $M A P 3 K \varepsilon 1 / 2$ and $M O B 1 A / 1 B$. (A,B): The aniline blue-stained dehiscent anthers of wild-type (WT) plants, showing the bright field image (A), the fluorescent image

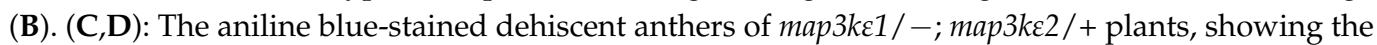
bright field image (C), the fluorescent image (D). (E,F): The aniline blue-stained dehiscent anthers of

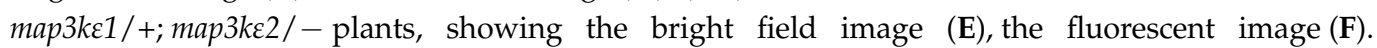


$(\mathbf{G}, \mathbf{H})$ : The aniline blue-stained dehiscent anthers mob1a/+; mob1b/- plants, showing the bright field image $(\mathbf{G})$, the fluorescent images $(\mathbf{H})$. $(\mathbf{I}, \mathbf{J})$ : The aniline blue-stained dehiscent anthers of

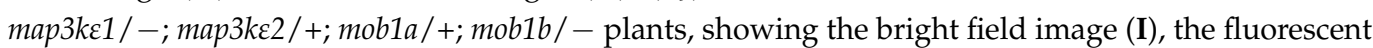

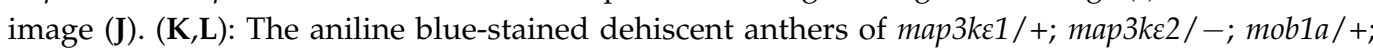
mob1b/ - plants, showing the bright field image (K), the fluorescent image (L). (M): Comparison of

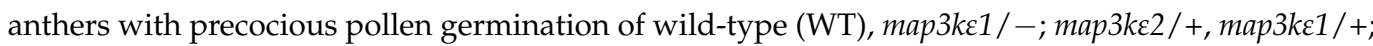


mob1a/+; mob1b/-. (N): Measurement of the JA contents in the opened flowers of map3ks1/-;

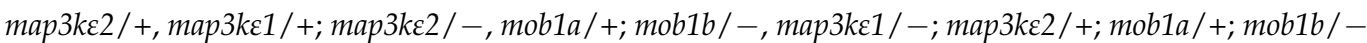

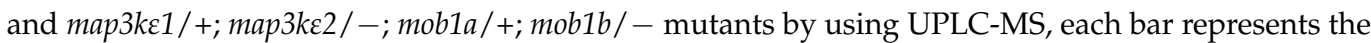
mean \pm SD of three independent experiments. Different letters represent significant difference at $\mathrm{ns}=$ not significant, ${ }^{* * * *} p<0.001$ (one-way ANOVA, Tukey post-test). Bars $=100 \mu \mathrm{m}$ in $(\mathbf{A}-\mathbf{L})$.

\subsection{Genetic Interaction between MYC2 and MOB1A/1B}

Due to the JA function in different plant development and MYC2 was a key regulator in the JA pathway. We analyzed the genetic interaction between the myc2-2 and mob1a/+; mob1b/- mutants, and used the mob1a/+; mob1b/- mutant plant as a female to cross with the myc2-2 plant. We performed characterization of the myc2-2/-; mob1a/+; mob1b/- triple mutants and the phenotypic showed $5.72 \%(n=62)$ of pollen germination in anthers of the myc2-2/-; mob1a/+; mob1b/- mutants and $10.72 \%(n=84)$ pollen germination in anthers of the mob1a/+; mob1b/- mutants (Figure 7). The precocious pollen germination of the mob1a/+; mob1b/- was slightly reduced by the myc2 mutant in myc2-2/-; mob1a/+; mob1b/mutants. These results suggested that genetic interaction between $M Y C 2$ and MOB1A/1B regulated pollen germination probably by JA signaling.
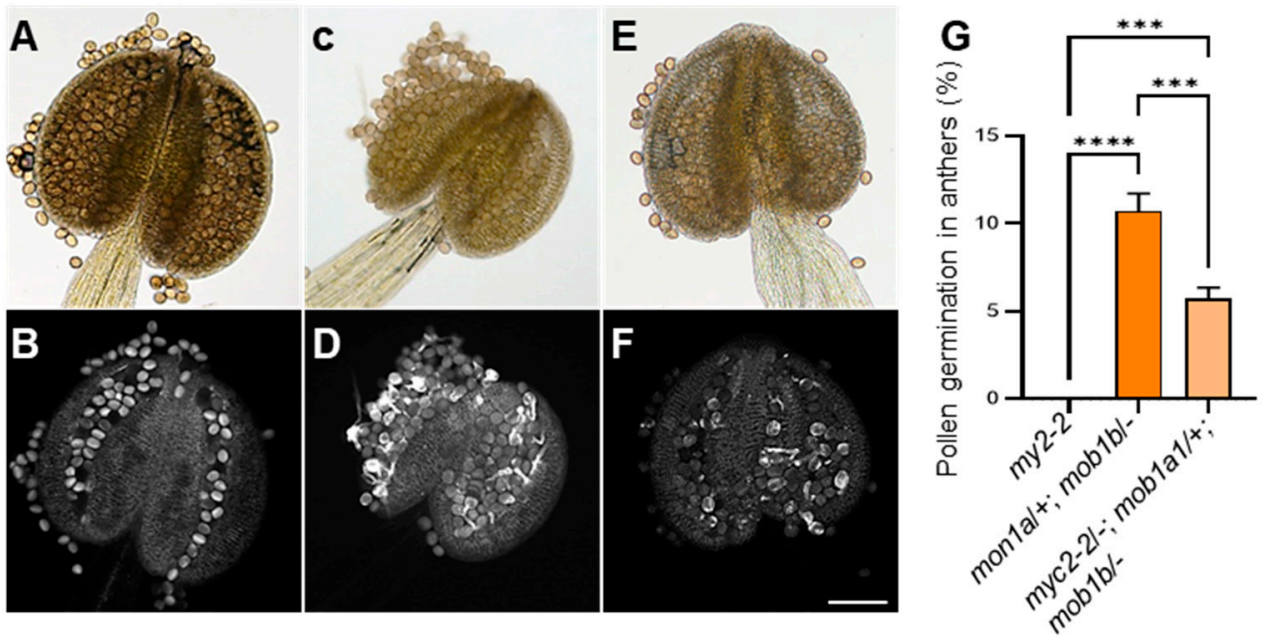

Figure 7. Genetic interaction of $M Y C 2$ and $M O B 1 A / 1 B$. (A,B): The aniline blue-stained dehiscent anthers of $m y c 2-2$ plants, showing the bright field image (A), the fluorescent image (B). (C,D): The aniline blue-stained dehiscent anthers of mob1a/ +; mob1b/ - plants, showing the bright field image (C), the fluorescent image (D). (E,F): The aniline blue-stained dehiscent anthers of myc2-2/ - ; mob1a/+; mob1b/ - plants, showing the bright field image (E), the fluorescent image (F). (G): A comparison of precocious pollen germination in the dehiscent anthers from myc2-2, mob1a/+; mob1b/-, myc2-2/-; mob1a/+; mob1b/-, each bar represents the mean \pm SD of three independent experiments. Different letters represent significant differences at ${ }^{* * *} p<0.001,{ }^{* * * *} p<0.0001$ (one-way ANOVA, Tukey post-test). Bars $=100 \mu \mathrm{m}$ in $(\mathbf{A}-\mathbf{F})$.

\section{Discussion}

3.1. MAP3KE1 and MAP3KE2 Functioned Redundantly and Involved in Control of Pollen Germination before Pollen Grains Landed on the Stigmas

MAPK cascades consist of three types of kinases, namely MAP kinase kinase kinases (MAPKKKs or MAP3Ks), MAP kinase kinases (MAPKKs or MAP2Ks) and MAP 
kinases (MAPKs). The Arabidopsis genome encodes 80 MAPKKKs, 10 MAPKKs and 20 MAPKs [40]. In plants, MAPK cascades regulate growth, development, stress responses, and immunity [41]. During plant reproduction, MAPK cascades regulate floral architecture, anther development, ovule development, and pollen tube guidance [42-46]. Several members of the MAPK cascades have been functionally characterized in Arabidopsis. The YODA(YDA), also known as MAPKKK4, affects zygote elongation and apical-basal polarity of the embryo [47] and the YDA-MKK4/5-MPK3/6 cascade is involved in regulating stomatal development, zygote elongation, asymmetric division of the zygote, and early embryo proper [41]. Arabidopsis NPK1-RELATED PROTEIN KINASE 1/2/3 (ANP1/2/3) belong to MAPKKKs, and the anp2 anp3 mapk4 triple-mutant combination is lethal to female gametophyte [48]. ANP3-MKK6-MPK4 cascade plays an important role in male-specific meiosis [49]. Nevertheless, very little is known about the roles of MAPKs in pollen development and germination. The molecular mechanism of MAPK involved pollen development and pollen tube growth remains largely unclear. MAP3K ss belong to MAPK kinase kinase kinase A4 sungroup and are required for pollen viability $[39,50]$. In this study, we further demonstrated that loss of the MAP3KEs function caused abnormal accumulation of callose, the elevation of JA, and precocious pollen germination in the dehiscent anthers, indicating that $M A P 3 K \varepsilon s$ had a complex mechanism underlying sexual plant reproduction.

The MAP3K $\varepsilon 1$ and MAP3K $\varepsilon 2$ shared homology with the Cdc7 and Cdc15 in yeast, which were the key components in the Hippo signaling pathway [28]. Our previous study demonstrated that the AGC kinases NDR2/4/5 interacted with the MOB1A/1B proteins in Arabidopsis, respectively, suggesting that the Hippo signaling components might be also existed in plants and played role in sexual plant reproduction [38]. This study showed that MAP3K $\varepsilon 1 / 2$ could interact with the MOB1A/1B proteins, but is unlikely to directly interact with NDR2/4/5, indicating that MAP3K $\varepsilon 1 / 2$ is also possibly related to the Hippo signaling pathway and involved in pollen germination in Arabidopsis.

\subsection{MAP3KE1/2 Controlled Pollen Germination Possibly by Crosstalk with JA Signaling}

The biosynthesis of JA and the expression of JA-dependent genes can be regulated by MAPKs. For example, cosilencing of the LeMPK1 and LeMPK2 reduces JA biosynthesis and the expression levels of JA-dependent defense genes in tomato [51]. Overexpression of OsMPK1 in rice leads to the accumulation of JA for disease resistance [52]. AtMPK9 and AtMPK12 in Arabidopsis are jointly involved in JA-induced stomatal closure [53,54]. OsMPK12 and OsMEK2 are activated by JA treatment during the defense response [55]. Besides, studies also show that JA is required for anther and pollen development [22,56]. In this work, we found that MAP3Kes may regulate pollen germination through crosstalk with JA. We found the JA content was greatly increased in the map $3 k \varepsilon 1 /-;$ map $3 \varepsilon 2 /+$ and

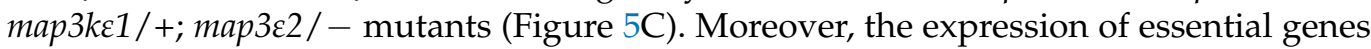
in JA biosynthetic, metabolic, and signaling pathway, such as LOX3, AOC2, JOX3, and $J A Z s$, were apparently upregulated in the map $3 k \varepsilon 1 /-;$ map $3 \varepsilon 2 /+$ and map $3 k \varepsilon 1 /+;$ map $3 \varepsilon 2 /-$ mutants (Figure 5A,B). In vitro pollen germination assays showed that application of 100 $\mu \mathrm{M}$ MeJA in the culture media could obviously enhance the germination rates of pollen, compared to the control medium (Figure S5M-Q). Recent study showed that disruption of $M Y C 2$ partially rescued the root developmental defect and JA hypersensitivity of mob1a/b mutant [37]. As well as, MYC2, MYC3, MYC4, and MYC5 were functionally redundant in stamen development and seed production [57]. We also performed characterization of the myc2-2/-; mob1a/+; mob1b/- triple mutant, and found that precocious pollen germination of the mob1a/+;mob1b/ - mutant could be slightly recovered by the myc2-2 mutation in myc2-2/-; mob1a/ +; mob1b/ - (Figure 7), indicating JA played a crucial role in pollen germination. Therefore, our results suggested that $M A P 3 K \varepsilon 1 / 2$ function in control of pollen germination, possibly through crosstalk with JA signaling pathway. Nevertheless, studies were required to further illustrate the mechanisms underlying the interaction of $M A P 3 K \varepsilon 1 / 2$ with JA signaling in control of pollen germination. 


\subsection{Callose May Be Involved in Regulation of Pollen Germination}

Many studies show that callose metabolism is very important for pollen germination and pollen tube growth. Callose is a $\beta-1,3$-linked homopolymer of glucan and plays an important role in a variety of processes in angiosperms, including plant development and stress response [58]. During microsporogenesis, the transient callose walls forms and wraps the pollen mother cells (PMCs) and their meiotic progeny (microspores), forming a tetrad. Then callose is hydrolyzed by $\beta$-1,3-glucanase secreted from the tapetum, releasing the free microspores [10]. In addition, the callose deposition also occurs during the pollen germination and pollen tube growth. Defects in the callose deposition could severely affect the microspore development and pollen tube growth [10,59]. For example, agp6 agp 11 and fla14 mutants display unusual callose deposition in the pollen grains and have precocious pollen germination in anthers [11,12]. Arabidopsis $r$ tg mutations also cause abnormal callose accumulation in the pollen grains, leading to precocious pollen germination in the anthers [8]. The mutations in the Arabidopsis GSL1/GSL10/CalS9 and overexpression of GSL2/CalS5 and PLANTACYANIN also result in abnormal callose accumulation in pollen grains and precocious pollen germination in the anthers $[9,10,60]$. Moreover, callose deposition can also be regulated by JA in plants. Arabidopsis OCP3 (Cationic peroxidase 3) is as one of JA negative regulators to decrease the callose deposition and weak defense for Botrytis cinerea and Plectosphaerella cucumerina [61]. During the defense of tomato against Botrytis cinerea, callose deposition requires a complete JA biosynthesis pathway [62,63]. Flg22 triggers a plant's innate immune response process-a COI-dependent JA signaling pathway that inhibits callose deposition [64]. In this study, our results showed that callose

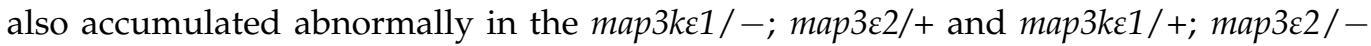
mutants (Figure $1 \mathrm{P}-\mathrm{U}, \mathrm{W}, \mathrm{X}$ ). The expression levels of callose synthetase genes, such as GSL2, GSL5, GSL7, GSL9, were significantly upregulated in the two double mutants (Figure S7A). Moreover, the expression levels of 1,3-glucanase genes, which were detected highly

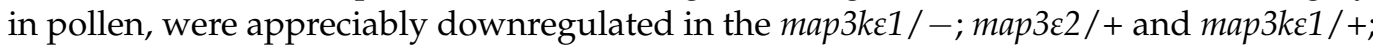
map3e2 / - mutants (Figure S7B). These results implied that the precocious pollen germina-

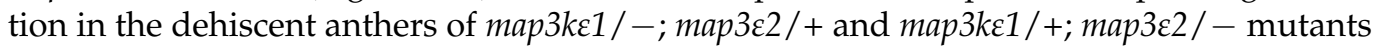
were likely associated with the abnormal callose accumulation in the pollen grains.

In this work, we found the MAP3K 11 and MAP3K $\varepsilon 2$ may be redundantly involved in the restriction of pollen germination before pollen grains landed on stigmas. Furthermore, MAP3K $\varepsilon 1 / 2$ could interact with MOB1A/1B proteins, suggesting that MAP3K $\varepsilon 1 / 2$ may interact with MOB1A/1B and played important roles in pollen germination possibly through crosstalk with JA and callose. Therefore, these findings provided the implications of MAP3K 1 1s in plant reproductive development and as potential materials in crop production.

\section{Materials and Methods}

\subsection{Plant Materials and Growth Conditions}

The wild-type and mutant plants of Arabidopsis thaliana used in this study were Colombian ecotypes (Col-0) background. The Arabidopsis T-DNA insertion mutants map3ke1 (SALK_133360C), map3ke2 (SALK_084747C), mob1a-1 (GK-719G04), mob1b-1 (SALK_062070C) were obtained from Arabidopsis Biological Resource Center (ABRC). All seeds were surface-sterilized with $8 \%$ bleach for $10 \mathrm{~min}$, then washed five times with sterile water, and plated on Murashige and Skoog (MS) media with or without $25 \mathrm{mg} / \mathrm{L}$ hygromycin [65]. After 2 days at $4{ }^{\circ} \mathrm{C}$, the plates were transferred to the growth chamber with $16 \mathrm{~h}$ light $/ 8 \mathrm{~h}$ dark cycles at $22{ }^{\circ} \mathrm{C}$ for 7 days. Then seedlings were transferred into soil and grown under the same condition. Sequences of all the primers used in the assays are listed in Table S1.

\section{2. $R T-P C R$ and $q R T-P C R$ Analysis}

The RNA samples from different tissues of Arabidopsis and tobacco leaves were extracted using a total RNA extraction kit (TIANGEN, DP441, Beijing, China). In total, $1 \mu \mathrm{g}$ 
RNA was reversely transcribed into cDNA using the RNA reversal kit (Gene-star, A224, Beijing, China). The RT-PCR assays were performed using the Taq PCR Star Mix (Gene-star, A012, China) and the program: $95^{\circ} \mathrm{C}$ for $3 \mathrm{~min}$, with 35 cycles of $95^{\circ} \mathrm{C}$ for $30 \mathrm{~s}$, and $52{ }^{\circ} \mathrm{C}$ for $30 \mathrm{~s}, 72{ }^{\circ} \mathrm{C}$ for $1 \mathrm{~min}$. TUBULIN8 was used as internal control [66]. Real-time PCR assays were performed using ABI Step One system (Thermo Fisher, Waltham, MA, USA) with Power SYBR Green PCR master mix (Gene-star, A303, Beijing, China) and followed by instructions of supplier's protocol, with the following program: $95^{\circ} \mathrm{C}$ for $10 \mathrm{~min}$, with 40 cycles of $95^{\circ} \mathrm{C}$ for $15 \mathrm{~s}$, and $60^{\circ} \mathrm{C}$ for $1 \mathrm{~min}$. All PCR reactions were performed in triplicates. ACTIN2 as internal control $[65,67]$. Sequences of all the primers used in the assays are listed in Table S1.

\subsection{Molecular Cloning and Transformation}

To analyze gene expression patterns, the promoter fragments of $M A P 3 K \varepsilon 1$ and $M A P 3 K \varepsilon 2$ genes were amplified by PCR using the gene-specific primer pairs (Table S1). The resulting promoter fragments were subcloned upstream of the GUS reporter gene in the modified pCAMBIA1300 vector (CAMBIA, Canberra, Australia) and introduced into wild-type plants using the Agrobacterium-mediated infiltration method [68]. GUS staining analysis was performed as previously described [69]. The transformants were screened on MS medium containing $25 \mathrm{mg} / \mathrm{L}$ hygromycin and used for evaluation of the complementation by phenotypic and genetic characterization. Sequences of all the primers used in the assays are listed in Table S1.

\subsection{Phenotypic Analyses}

Morphology of the pollen grains was observed using scanning electron microscopy (TM4000, HITACHI, Tokyo, Japan) [70]. The pollen viability was assayed by Alexander's staining as described in previous work [71]. Then, $4^{\prime} 6$-diamidino-2-phenylindole (DAPI) staining of pollen grains was performed to visualize the nuclei in pollen grains as described previously [72,73]. Aniline blue is a specific dye for callose. The pollen grains or anthers were stained with a solution containing $0.1 \%$ aniline blue in $0.1 \mathrm{M} \mathrm{K}_{2} \mathrm{HPO}_{4}-\mathrm{KOH}$ buffer $(\mathrm{pH}=11.0)$ for 5-10 min. Fluorescent images were obtained with a Leica DM2500 microscope (Leica, Wetzlar, Germany) under UV light [38].

For pollen in vitro germination assay, pollen grains were collected and spread on the pollen germination medium containing $20 \mathrm{mM} \mathrm{CaCl}_{2}, 20 \mathrm{mM} \mathrm{Ca}\left(\mathrm{NO}_{3}\right)_{2}, 20 \mathrm{mM} \mathrm{MgSO}_{4}$, $0.2 \% \mathrm{H}_{3} \mathrm{BO}_{4}, 1.8 \%$ sucrose, and $0.1 \%$ agarose. After incubation in the darkness at $28{ }^{\circ} \mathrm{C}$, pollen germination was examined as previously described [66,74].

\subsection{Yeast Two-Hybrid Assays}

Yeast two-hybrid analysis was performed using Gal4 system vector (Clontech, https: / / www.takarabio.com/assets/a/112933, accessed on 20 February 2022). The coding sequences (CDSs) of $M A P 3 K \varepsilon 1$ and $M A P 3 K \varepsilon 2$ were cloned into the vector pGADT7 (AD), and $M O B 1 A$ and $M O B 1 B$ cDNA fragments were cloned into pGBKT7 (BD), respectively. Then constructs were co-transformed into yeast strain AH109 and then grow on SD/-Leu-Trp plates at $28^{\circ} \mathrm{C}$ for 3 days. The colonies were identified by PCR, and positive colonies then continued to culture until the $\mathrm{OD}_{600}$ was $0.4 \sim 0.6$, and transferred to grow on SD/ - Leu-Trp plates and SD/-Trp-Leu-His for 3-7 days at $28^{\circ} \mathrm{C}$, respectively [75]. Sequences of all the primers used in the assays are listed in Table S1.

\subsection{Firefly Luciferase Complementation Imaging Assay}

The CDSs of $M O B 1 A$ or $M O B 1 B$ were fused to the upstream of N-Luc in the PCAMBIANLuc vector, and $M A P 3 K \varepsilon 1$ or $M A P 3 K \varepsilon 2$ was fused to the downstream of C-Luc in the pCAMBIA-CLuc vector, respectively. The resulting constructs were transformed into Agrobacterium strain GV3101, which cultured in the medium containing $10 \mathrm{mM} \mathrm{MgCl}$, $10 \mathrm{mM}$ MES, pH 5.7, $200 \mu \mathrm{M}$ Acetosyringone, and then infiltrated into N. benthamiana leaves. CLuc-GUS and GUS-Nluc were used as negative control, and STG1-Nluc and Cluc- 
RAR1 were used as positive control [76]. After infiltration for 2-4 days, $1 \mathrm{mM}$ D-luciferin was sprayed on the $N$. benthamiana leaves and kept in the darkness for $5 \mathrm{~min}$, and the cooling CCD imaging system was used to capture LUC images with 8 to 10 min exposure time $[65,77]$.

\subsection{Co-Immunoprecipitation Assay}

The Co-IP assay in N. benthamiana leaves was performed as described [78]. The total proteins were extracted from $N$. benthamiana leaves expressing pUBQ10::GFP-MAP3KE1/ pUBQ10::MOB1A-mcherry or pUBQ10::GFP-MAP3KE1/pUBQ10::MOB1A-mcherry constructs with IP buffer containing $50 \mathrm{mM}$ HEPES, pH = 7.4, $50 \mathrm{mM} \mathrm{NaCl}, 0.1 \%$ Triton X-100, $10 \mathrm{mM}$ EGTA, $\mathrm{pH}=8.0,1 \mathrm{mM}$ NaF, $100 \mathrm{mM}$ DTT and $1 \times$ cocktail. In total, $50 \mu \mathrm{L}$ was used as input detection, and the rest was incubated gently with anti-GFP agarose beads (AlpaLife, Shenzhen, China) at $4{ }^{\circ} \mathrm{C}$ for $2 \mathrm{~h}$. After incubation, the agarose beads were washed five times with IP buffer and boiled for $10 \mathrm{~min}$. The immunoprecipitated samples were finally separated on a $10 \%(w / v)$ SDS-PAGE and subjected to immunoblotting analysis with anti-GFP (EASYBIO, Beijing, China) and anti-mcherry antibody (EASYBIO, Beijing, China), respectively. The resulting images were recorded using the Fusion FX6 (Vilber, Paris, France) system. Further, pUBQ10::GFP-MAP3Ke1/pUBQ10::MOB1B-mcherry or pUBQ10::GFP$M A P 3 K \varepsilon 1 / 2 / p U B Q 10:: M O B 1 B$-mcherry combinations were as described above.

\subsection{Subcellular Localization}

For the location of proteins, the full-length cDNA sequences of $M A P 3 K \varepsilon 1$ and $M A P 3 K \varepsilon 2$ were fused to the pCAMBIA1390-GFP vector by homologous recombination (Transgen, CU201-02, Beijing, China), and the full-length CDSs of $M O B 1 A$ and $M O B 1 B$ were fused to the pCAMBIA1390-mcherry vector. The resulting constructs were introduced into wildtype (WT) plants. The transgenic plants from both GFP-MAP3K $\varepsilon 1$ and MOB1A-mcherry were selected in MS media containing $25 \mathrm{mg} / \mathrm{L}$ hygromycin. We observed the root using confocal laser scanning microscopy (CLSM, Zeiss LSM880 META microscope, Carl Zeiss, Oberkochen, Germany, https: / www.zeiss.com.cn/microscopy/products/confocalmicroscopes.html, accessed on 20 February 2022) data and collected images. The GFP signals at 500-550 $\mathrm{nm}$ were collected using the excitation light at $488 \mathrm{~nm}$. The mcherry signals were excited at $561 \mathrm{~nm}$ and collected at 590-665 nm [65]. Additionally, GFPMAP3K $\varepsilon 1 / M O B 1 B-m c h e r r y$ or GFP-MAP3K $\varepsilon 1 / 2$ and MOB1B-mcherry combinations were as described above.

\subsection{Measurement of JA and Callose}

The flowers at the floral developmental stage 13 from wild-type (WT), map3ke1/-;

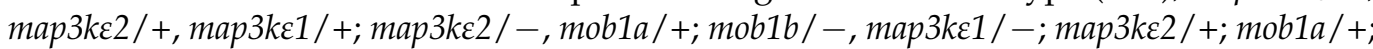

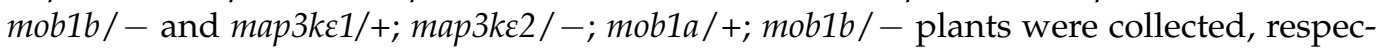
tively, and placed in liquid nitrogen for quick-freezing preservation. In total, $50 \mathrm{mg}$ powder was transferred into a $2 \mathrm{~mL}$ centrifuge tube, extracted with isopropanol solution, and then chloroform. The organic phase was finally blown dry at room temperature with nitrogen, and then solubilized with $0.1 \mathrm{~mL}$ of methanol before detection. The determination of JA was performed by ultraperformance liquid chromatography (UPLC) coupled with mass spectrometry [79].

Measurement of pollen callose was performed as described by Jones et al. [80]. Fluorescent signals were collected using a Spark ${ }^{\circledR}$ (Zurich, Switzerland, https: / / lifesciences.tecan. $\mathrm{cn} /$ multimode-plate-reader, accessed on 20 February 2022). The excitation wavelength was $400 \mathrm{~nm}$, the emission wavelength was $500 \mathrm{~nm}$.

Supplementary Materials: The following supporting information can be downloaded at: https: / / www.mdpi.com/article/10.3390/ijms23052683/s1. 
Author Contributions: J.M., X.Z. and L.C. conceived and designed the experiments. J.M. conducted all experiments. P.Z. took part in performing the statistics on the abnormal accumulation of pollen callose. Y.Z. and B.S. helped with the mutant identification. J.M., D.Y., X.Z. and L.C. revised the manuscript. All authors have read and agreed to the published version of the manuscript.

Funding: This work was supported by the Natural Science Foundation of China (NSFC, No. 31970337).

Institutional Review Board Statement: Not applicable.

Informed Consent Statement: Not applicable.

Data Availability Statement: We do not report additional data.

Acknowledgments: We thank the professors from the College of Biological Sciences, China Agricultural University, Beijing, China: Wenkun Zhou for the gift of the myc2-2 mutant seeds, Yan Guo for the gift of the pUBQ10::GFP/mcherry plasmids, Yan Li for the gift of the STG1-Nluc and Cluc-RAR1, and Zhen Li for the technical assistance with UPLC.

Conflicts of Interest: The authors declare no conflict of interest.

\section{References}

1. Cheung, A.Y.; Boavida, L.C.; Aggarwal, M.; Wu, H.M.; Feijo, J.A. The pollen tube journey in the pistil and imaging the in vivo process by two-photon microscopy. J. Exp. Bot. 2010, 61, 1907-1915. [CrossRef] [PubMed]

2. Hamamura, Y.; Nagahara, S.; Higashiyama, T. Double fertilization on the move. Curr. Opin. Plant Biol. 2012, 15, 70-77. [CrossRef]

3. Malho, R.; Liu, Q.; Monteiro, D.; Rato, C.; Camacho, L.; Dinis, A. Signalling pathways in pollen germination and tube growth Protoplasma 2006, 228, 21-30. [CrossRef]

4. Zhang, D.; Wengier, D.; Shuai, B.; Gui, C.P.; Muschietti, J.; McCormick, S.; Tang, W.H. The pollen receptor kinase LePRK2 mediates growth-promoting signals and positively regulates pollen germination and tube growth. Plant Physiol. 2008, 148, 1368-1379. [CrossRef] [PubMed]

5. Sirova, J.; Sedlarova, M.; Piterkova, J.; Luhova, L.; Petrivalsky, M. The role of nitric oxide in the germination of plant seeds and pollen. Plant Sci. 2011, 181, 560-572. [CrossRef] [PubMed]

6. Gao, X.Q.; Liu, C.Z.; Li, D.D.; Zhao, T.T.; Li, F.; Jia, X.N.; Zhao, X.Y.; Zhang, X.S. The Arabidopsis KIN $\beta \gamma$ subunit of the SnRK1 complex regulates pollen hydration on the stigma by mediating the level of reactive oxygen species in pollen. PLoS Genet. 2016, 12, e1006228. [CrossRef]

7. Chen, W.; Jia, P.F.; Yang, W.C.; Li, H.J. Plasma membrane H(+)-ATPases-mediated cytosolic proton gradient regulates pollen tube growth. J. Integr. Plant Biol. 2020, 62, 1817-1822. [CrossRef]

8. Johnson, S.A.; McCormick, S. Pollen germinates precociously in the anthers of raring-to-go, an Arabidopsis gametophytic Mutant. Plant Physiol. 2001, 126, 685-695. [CrossRef]

9. Dong, J.; Kim, S.T.; Lord, E.M. Plantacyanin plays a role in reproduction in Arabidopsis. Plant Physiol. 2005, 138, 778-789. [CrossRef]

10. Xie, B.; Wang, X.; Hong, Z. Precocious pollen germination in Arabidopsis plants with altered callose deposition during microsporogenesis. Planta 2010, 231, 809-823. [CrossRef]

11. Coimbra, S.; Costa, M.; Mendes, M.A.; Pereira, A.M.; Pinto, J.; Pereira, L.G. Early germination of Arabidopsis pollen in a double null mutant for the arabinogalactan protein genes AGP6 and AGP11. Sex. Plant Reprod. 2010, 23, 199-205. [CrossRef] [PubMed]

12. Miao, Y.; Cao, J.; Huang, L.; Yu, Y.; Lin, S. FLA14 is required for pollen development and preventing premature pollen germination under high humidity in Arabidopsis. BMC Plant Biol. 2021, 21, 254. [CrossRef] [PubMed]

13. Hashida, S.N.; Takahashi, H.; Takahara, K.; Kawai-Yamada, M.; Kitazaki, K.; Shoji, K.; Goto, F.; Yoshihara, T.; Uchimiya, H. NAD+ accumulation during pollen maturation in Arabidopsis regulating onset of germination. Mol. Plant 2013, 6, 216-225. [CrossRef] [PubMed]

14. Yang, X.; Zhang, Q.; Zhao, K.; Luo, Q.; Bao, S.; Liu, H.; Men, S. The Arabidopsis GPR1 gene negatively affects pollen germination, pollen tube growth, and gametophyte senescence. Int. J. Mol. Sci. 2017, 18, 1303. [CrossRef] [PubMed]

15. Turner, J.G.; Ellis, C.; Devoto, A. The jasmonate signal pathway. Plant Cell 2002, 14 (Suppl. S1), S153-S164. [CrossRef]

16. Browse, J. Jasmonate passes muster: A receptor and targets for the defense hormone. Annu. Rev. Plant Biol. 2009, 60, 183-205. [CrossRef]

17. McConn, M.; Browse, J. The critical requirement for linolenic acid is pollen development, not photosynthesis, in an Arabidopsis mutant. Plant Cell 1996, 8, 403-416. [CrossRef]

18. Xie, D.X.; Feys, B.F.; James, S.; Nieto-Rostro, M.; Turner, J.G. COI1: An Arabidopsis gene required for jasmonate-regulated defense and fertility. Science 1998, 280, 1091-1094. [CrossRef]

19. Stintzi, A.; Browse, J. The Arabidopsis male-sterile mutant, opr3, lacks the 12-oxophytodienoic acid reductase required for jasmonate synthesis. Proc. Natl. Acad. Sci. USA 2000, 97, 10625-10630. [CrossRef]

20. Sanders, P.M.; Lee, P.Y.; Biesgen, C.; Boone, J.D.; Beals, T.P.; Weiler, E.W.; Goldberg, R.B. The Arabidopsis DELAYED DEHISCENCE1 gene encodes an enzyme in the jasmonic acid synthesis pathway. Plant Cell 2000, 12, 1041-1061. [CrossRef] 
21. von Malek, B.; van der Graaff, E.; Schneitz, K.; Keller, B. The Arabidopsis male-sterile mutant dde2-2 is defective in the ALLENE OXIDE SYNTHASE gene encoding one of the key enzymes of the jasmonic acid biosynthesis pathway. Planta 2002, 216, 187-192. [CrossRef] [PubMed]

22. Ishiguro, S.; Kawai-Oda, A.; Ueda, J.; Nishida, I.; Okada, K. The DEFECTIVE IN ANTHER DEHISCIENCE gene encodes a novel phospholipase A1 catalyzing the initial step of jasmonic acid biosynthesis, which synchronizes pollen maturation, anther dehiscence, and flower opening in Arabidopsis. Plant Cell 2001, 13, 2191-2209. [CrossRef] [PubMed]

23. Park, J.H.; Halitschke, R.; Kim, H.B.; Baldwin, I.T.; Feldmann, K.A.; Feyereisen, R. A knock-out mutation in allene oxide synthase results in male sterility and defective wound signal transduction in Arabidopsis due to a block in jasmonic acid biosynthesis. Plant J. 2002, 31, 1-12. [CrossRef] [PubMed]

24. Cetinbas-Genc, A.; Vardar, F. Effect of methyl jasmonate on in-vitro pollen germination and tube elongation of Pinus nigra. Protoplasma 2020, 257, 1655-1665. [CrossRef] [PubMed]

25. Li, X.R.; Li, H.J.; Yuan, L.; Liu, M.; Shi, D.Q.; Liu, J.; Yang, W.C. Arabidopsis DAYU/ABERRANT PEROXISOME MORPHOLOGY9 is a key regulator of peroxisome biogenesis and plays critical roles during pollen maturation and germination in planta. Plant Cell 2014, 26, 619-635. [CrossRef] [PubMed]

26. Ju, Y.; Guo, L.; Cai, Q.; Ma, F.; Zhu, Q.Y.; Zhang, Q. Sodmergen, Arabidopsis JINGUBANG is a negative regulator of pollen germination that prevents pollination in moist environments. Plant Cell 2016, 28, 2131-2146. [CrossRef]

27. Group, M.; Ichimura, K.; Shinozaki, K.; Tena, G.; Sheen, J.; Henry, Y.; Champion, A.; Kreis, M.; Zhang, S.; Hirt, H.; et al. Mitogen-activated protein kinase cascades in plants: A new nomenclature. Trends Plant Sci. 2002, 7, 301-308.

28. Jouannic, S.; Champion, A.; Segui-Simarro, J.M.; Salimova, E.; Picaud, A.; Tregear, J.; Testillano, P.; Risueno, M.C.; Simanis, V.; Kreis, M.; et al. The protein kinases AtMAP3Kepsilon1 and BnMAP3Kepsilon1 are functional homologues of S. pombe cdc7p and may be involved in cell division. Plant J. 2001, 26, 637-649. [CrossRef]

29. Simanis, V. Events at the end of mitosis in the budding and fission yeasts. J. Cell Sci. 2003, 116 Pt 21, 4263-4275. [CrossRef]

30. Bettignies, G.; Johnston, L.H. The mitotic exit network. Curr. Biol. 2003, 13, R301. [CrossRef]

31. Maerz, S.; Seiler, S. Tales of RAM and MOR: NDR kinase signaling in fungal morphogenesis. Curr. Opin. Microbiol. 2010, 13, 663-671. [CrossRef] [PubMed]

32. Hergovich, A.; Hemmings, B.A. Hippo signalling in the G2/M cell cycle phase: Lessons learned from the yeast MEN and SIN pathways. Semin. Cell Dev. Biol. 2012, 23, 794-802. [CrossRef] [PubMed]

33. Xiong, J.; Cui, X.; Yuan, X.; Yu, X.; Sun, J.; Gong, Q. The Hippo/STE20 homolog SIK1 interacts with MOB1 to regulate cell proliferation and cell expansion in Arabidopsis. J. Exp. Bot. 2016, 67, 1461-1475. [CrossRef]

34. Galla, G.; Zenoni, S.; Marconi, G.; Marino, G.; Botton, A.; Pinosa, F.; Citterio, S.; Ruperti, B.; Palme, K.; Albertini, E.; et al. Sporophytic and gametophytic functions of the cell cycle-associated Mob1 gene in Arabidopsis thaliana L. Gene 2011, 484, 1-12 [CrossRef] [PubMed]

35. Pinosa, F.; Begheldo, M.; Pasternak, T.; Zermiani, M.; Paponov, I.A.; Dovzhenko, A.; Barcaccia, G.; Ruperti, B.; Palme, K. The Arabidopsis thaliana Mob1A gene is required for organ growth and correct tissue patterning of the root tip. Ann. Bot. 2013, 112, 1803-1814. [CrossRef] [PubMed]

36. Cui, X.; Guo, Z.; Song, L.; Wang, Y.; Cheng, Y. NCP1/AtMOB1A plays key roles in auxin-mediated Arabidopsis development. PLoS Genet. 2016, 12, e1005923. [CrossRef]

37. Guo, Z.; Yue, X.; Cui, X.; Song, L.; Cheng, Y. AtMOB1 genes regulate jasmonate accumulation and plant development. Plant Physiol. 2020, 182, 1481-1493. [CrossRef]

38. Zhou, P.M.; Liang, Y.; Mei, J.; Liao, H.Z.; Wang, P.; Hu, K.; Chen, L.Q.; Zhang, X.Q.; Ye, D. The Arabidopsis AGC kinases NDR2/4/5 interact with MOB1A/1B and play important roles in pollen development and germination. Plant J. 2021, 105, 1035-1052. [CrossRef]

39. Chaiwongsar, S.; Otegui, M.S.; Jester, P.J.; Monson, S.S.; Krysan, P.J. The protein kinase genes MAP3K epsilon 1 and MAP3K epsilon 2 are required for pollen viability in Arabidopsis thaliana. Plant J. 2006, 48, 193-205. [CrossRef]

40. Colcombet, J.; Hirt, H. Arabidopsis MAPKs: A complex signaling network involved in multiple biological processes. Biochem. J. 2008, 413, 217-226. [CrossRef]

41. Wang, Z.; Gou, X. Receptor-like protein kinases function upstream of MAPKs in regulating plant development. Int. J. Mol. Sci. 2020, 21, 7638. [CrossRef] [PubMed]

42. Bush, S.M.; Krysan, P.J. Mutational evidence that the Arabidopsis MAP kinase MPK6 is involved in anther, inflorescence, and embryo development. J. Exp. Bot. 2007, 58, 2181-2191. [CrossRef] [PubMed]

43. Wang, H.; Liu, Y.; Bruffett, K.; Lee, J.; Hause, G.; Walker, J.C.; Zhang, S. Haplo-insufficiency of MPK3 in MPK6 mutant background uncovers a novel function of these two MAPKs in Arabidopsis ovule development. Plant Cell 2008, 20, 602-613. [CrossRef]

44. Hord, C.L.; Sun, Y.J.; Pillitteri, L.J.; Torii, K.U.; Wang, H.; Zhang, S.; Ma, H. Regulation of Arabidopsis early anther development by the mitogen-activated protein kinases, MPK3 and MPK6, and the ERECTA and related receptor-like kinases. Mol. Plant 2008, 1, 645-658. [CrossRef] [PubMed]

45. Meng, X.; Wang, H.; He, Y.; Liu, Y.; Walker, J.C.; Torii, K.U.; Zhang, S. A MAPK cascade downstream of ERECTA receptor-like protein kinase regulates Arabidopsis inflorescence architecture by promoting localized cell proliferation. Plant Cell 2012, 24, 4948-4960. [CrossRef] 
46. Guan, Y.; Lu, J.; Xu, J.; McClure, B.; Zhang, S. Two mitogen-activated protein kinases, MPK3 and MPK6, are required for funicular guidance of pollen tubes in Arabidopsis. Plant Physiol. 2014, 165, 528-533. [CrossRef]

47. Lukowitz, W.; Roeder, A.; Parmenter, D.; Somerville, C. A MAPKK kinase gene regulates extra-embryonic cell fate in Arabidopsis. Cell 2004, 116, 109-119. [CrossRef]

48. Su, S.H.; Krysan, P.J. A double-mutant collection targeting MAP kinase related genes in Arabidopsis for studying genetic interactions. Plant J. 2016, 88, 867-878. [CrossRef]

49. Zeng, Q.; Chen, J.G.; Ellis, B.E. AtMPK4 is required for male-specific meiotic cytokinesis in Arabidopsis. Plant J. 2011, 67, 895-906. [CrossRef]

50. Xu, J.; Zhang, S. Mitogen-activated protein kinase cascades in signaling plant growth and development. Trends Plant Sci. 2015, 20, 56-64. [CrossRef]

51. Kandoth, P.K.; Ranf, S.; Pancholi, S.S.; Jayanty, S.; Walla, M.D.; Miller, W.; Howe, G.A.; Lincoln, D.E.; Stratmann, J.W. Tomato MAPKs LeMPK1, LeMPK2, and LeMPK3 function in the systemin-mediated defense response against herbivorous insects. Proc. Natl. Acad. Sci. USA 2007, 104, 12205-12210. [CrossRef]

52. Shen, X.; Yuan, B.; Liu, H.; Li, X.; Xu, C.; Wang, S. Opposite functions of a rice mitogen-activated protein kinase during the process of resistance against Xanthomonas oryzae. Plant J. 2010, 64, 86-99. [CrossRef] [PubMed]

53. de Zelicourt, A.; Colcombet, J.; Hirt, H. The role of MAPK modules and ABA during abiotic stress signaling. Trends Plant Sci. 2016, 21, 677-685. [CrossRef] [PubMed]

54. Lee, Y.; Kim, Y.J.; Kim, M.H.; Kwak, J.M. MAPK cascades in guard cell signal transduction. Front. Plant Sci. 2016, 7, 80. [CrossRef] [PubMed]

55. Min, K.Y.; Oh, S.I.; Ok, S.H.; Cho, S.K.; Shin, J.S. Identification of putative MAPK kinases in Oryza minuta and O. sativa responsive to biotic stresses. Mol. Cells 2007, 23, 108-114.

56. Wilson, Z.A.; Song, J.; Taylor, B.; Yang, C. The final split: The regulation of anther dehiscence. J. Exp. Bot. 2011, 62, 1633-1649. [CrossRef]

57. Qi, T.; Huang, H.; Song, S.; Xie, D. Regulation of jasmonate-mediated stamen development and seed production by a bHLH-MYB complex in Arabidopsis. Plant Cell 2015, 27, 1620-1633. [CrossRef]

58. Shi, X.; Han, X.; Lu, T.G. Callose synthesis during reproductive development in monocotyledonous and dicotyledonous plants. Plant Signal. Behav. 2016, 11, e1062196. [CrossRef]

59. Lu, P.; Chai, M.; Yang, J.; Ning, G.; Wang, G.; Ma, H. The Arabidopsis CALLOSE DEFECTIVE MICROSPORE1 gene is required for male fertility through regulating callose metabolism during microsporogenesis. Plant Physiol. 2014, 164, 1893-1904. [CrossRef]

60. Enns, L.C.; Kanaoka, M.M.; Torii, K.U.; Comai, L.; Okada, K.; Cleland, R.E. Two callose synthases, GSL1 and GSL5, play an essential and redundant role in plant and pollen development and in fertility. Plant Mol. Biol. 2005, 58, 333-349. [CrossRef]

61. Garcia-Andrade, J.; Ramirez, V.; Flors, V.; Vera, P. Arabidopsis ocp3 mutant reveals a mechanism linking ABA and JA to pathogen-induced callose deposition. Plant J. 2011, 67, 783-794. [CrossRef] [PubMed]

62. Scalschi, L.; Sanmartin, M.; Camanes, G.; Troncho, P.; Sanchez-Serrano, J.J.; Garcia-Agustin, P.; Vicedo, B. Silencing of OPR3 in tomato reveals the role of OPDA in callose deposition during the activation of defense responses against Botrytis cinerea. Plant $J$. 2015, 81, 304-315. [CrossRef] [PubMed]

63. Sanmartin, N.; Pastor, V.; Pastor-Fernandez, J.; Flors, V.; Pozo, M.J.; Sanchez-Bel, P. Role and mechanisms of callose priming in mycorrhiza-induced resistance. J. Exp. Bot. 2020, 71, 2769-2781. [CrossRef] [PubMed]

64. Wu, S.W.; Kumar, R.; Iswanto, A.B.B.; Kim, J.Y. Callose balancing at plasmodesmata. J. Exp. Bot. 2018, 69, 5325-5339. [CrossRef] [PubMed]

65. Liao, H.Z.; Zhu, M.M.; Cui, H.H.; Du, X.Y.; Tang, Y.; Chen, L.Q.; Ye, D.; Zhang, X.Q. MARIS plays important roles in Arabidopsis pollen tube and root hair growth. J. Integr. Plant Biol. 2016, 58, 927-940. [CrossRef]

66. Cui, H.H.; Liao, H.Z.; Tang, Y.; Du, X.Y.; Chen, L.Q.; Ye, D.; Zhang, X.Q. ABORTED GAMETOPHYTE 1 is required for gametogenesis in Arabidopsis. J. Integr. Plant Biol. 2015, 57, 1003-1016. [CrossRef]

67. Zhu, L.; Chu, L.C.; Liang, Y.; Zhang, X.Q.; Chen, L.Q.; Ye, D. The Arabidopsis CrRLK1L protein kinases BUPS1 and BUPS2 are required for normal growth of pollen tubes in the pistil. Plant J. 2018, 95, 474-486. [CrossRef]

68. Clough, S.J.; Bent, A.F. Floral dip: A simplified method for Agrobacterium-mediated transformation of Arabidopsis thaliana. Plant J. 1998, 16, 735-743. [CrossRef]

69. Liang, Y.; Tan, Z.M.; Zhu, L.; Niu, Q.K.; Zhou, J.J.; Li, M.; Chen, L.Q.; Zhang, X.Q.; Ye, D. MYB97, MYB101 and MYB120 function as male factors that control pollen tube-synergid interaction in Arabidopsis thaliana fertilization. PLoS Genet. 2013, 9, e1003933. [CrossRef]

70. Jiang, L.; Yang, S.L.; Xie, L.F.; Puah, C.S.; Zhang, X.Q.; Yang, W.C.; Sundaresan, V.; Ye, D. VANGUARD1 encodes a pectin methylesterase that enhances pollen tube growth in the Arabidopsis style and transmitting tract. Plant Cell $2005,17,584-596$. [CrossRef]

71. Liu, X.L.; Liu, L.; Niu, Q.K.; Xia, C.; Yang, K.Z.; Li, R.; Chen, L.Q.; Zhang, X.Q.; Zhou, Y.; Ye, D. Male gametophyte defective 4 encodes a rhamnogalacturonan II xylosyltransferase and is important for growth of pollen tubes and roots in Arabidopsis. Plant $J$. 2011, 65, 647-660. [CrossRef] 
72. Yang, K.Z.; Xia, C.; Liu, X.L.; Dou, X.Y.; Wang, W.; Chen, L.Q.; Zhang, X.Q.; Xie, L.F.; He, L.; Ma, X.; et al. A mutation in Thermosensitive Male Sterile 1, encoding a heat shock protein with DnaJ and PDI domains, leads to thermosensitive gametophytic male sterility in Arabidopsis. Plant J. 2009, 57, 870-882. [CrossRef] [PubMed]

73. Dou, X.Y.; Yang, K.Z.; Ma, Z.X.; Chen, L.Q.; Zhang, X.Q.; Bai, J.R.; Ye, D. AtTMEM18 plays important roles in pollen tube and vegetative growth in Arabidopsis. J. Integr. Plant Biol. 2016, 58, 679-692. [CrossRef] [PubMed]

74. Jia, D.J.; Cao, X.; Wang, W.; Tan, X.Y.; Zhang, X.Q.; Chen, L.Q.; Ye, D. GNOM-LIKE 2, encoding an adenosine diphosphateribosylation factor-guanine nucleotide exchange factor protein homologous to GNOM and GNL1, is essential for pollen germination in Arabidopsis. J. Integr. Plant Biol. 2009, 51, 762-773. [CrossRef]

75. Tang, Y.; Yin, Z.; Zeng, Y.; Zhang, Q.; Chen, L.; He, Y.; Lu, P.; Ye, D.; Zhang, X. MTOPVIB interacts with AtPRD1 and plays important roles in formation of meiotic DNA double-strand breaks in Arabidopsis. Sci. Rep. 2017, 7, 10007. [CrossRef] [PubMed]

76. Chen, H.; Zou, Y.; Shang, Y.; Lin, H.; Wang, Y.; Cai, R.; Tang, X.; Zhou, J.M. Firefly luciferase complementation imaging assay for protein-protein interactions in plants. Plant Physiol. 2008, 146, 368-376. [CrossRef] [PubMed]

77. Li, J.; Zhou, H.; Zhang, Y.; Li, Z.; Yang, Y.; Guo, Y. The GSK3-like Kinase BIN2 is a molecular switch between the salt stress response and growth recovery in Arabidopsis thaliana. Dev. Cell 2020, 55, 367-380.e6. [CrossRef] [PubMed]

78. Ding, Y.; Li, H.; Zhang, X.; Xie, Q.; Gong, Z.; Yang, S. OST1 kinase modulates freezing tolerance by enhancing ICE1 stability in Arabidopsis. Dev. Cell 2015, 32, 278-289. [CrossRef]

79. Fu, J.; Chu, J.; Sun, X.; Wang, J.; Yan, C. Simple, rapid, and simultaneous assay of multiple carboxyl containing phytohormones in wounded tomatoes by UPLC-MS/MS using single SPE purification and isotope dilution. Anal. Sci. 2012, 28, 1081-1087. [CrossRef]

80. Jones, D.L.; Blancaflor, E.B.; Kochian, L.V.; Gilroy, S. Spatial coordination of aluminium uptake, production of reactive oxygen species, callose production and wall rigidification in maize roots. Plant Cell Environ. 2006, 29, 1309-1318. [CrossRef] 